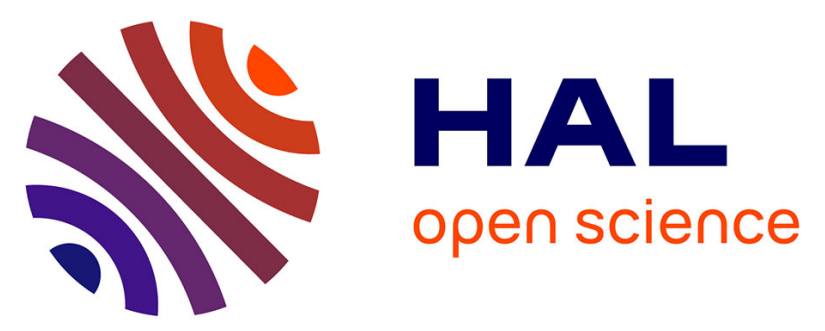

\title{
The K\&C PALSAR mosaic of the African continent: processing issues and first thematic results
}

Gianfranco D. de Grandi, Alexandre Bouvet, Richard M. Lucas, Masanobu Shimada, Stefano Monaco, Ake Rosenqvist

\section{- To cite this version:}

Gianfranco D. de Grandi, Alexandre Bouvet, Richard M. Lucas, Masanobu Shimada, Stefano Monaco, et al.. The K\&C PALSAR mosaic of the African continent: processing issues and first thematic results. IEEE Transactions on Geoscience and Remote Sensing, 2011, 49 (10), pp.3593-3610. 10.1109/TGRS.2011.2165288 . hal-00629878

\section{HAL Id: hal-00629878 https://hal.science/hal-00629878}

Submitted on 6 Oct 2011

HAL is a multi-disciplinary open access archive for the deposit and dissemination of scientific research documents, whether they are published or not. The documents may come from teaching and research institutions in France or abroad, or from public or private research centers.
L'archive ouverte pluridisciplinaire HAL, est destinée au dépôt et à la diffusion de documents scientifiques de niveau recherche, publiés ou non, émanant des établissements d'enseignement et de recherche français ou étrangers, des laboratoires publics ou privés. 


\title{
The K\&C PALSAR Mosaic of the African Continent: Processing Issues and First Thematic Results
}

\author{
Gianfranco D. De Grandi, Fellow, IEEE, Alexandre Bouvet, Richard M. Lucas, \\ Masanobu Shimada, Fellow, IEEE, Stefano Monaco, and Ake Rosenqvist
}

\begin{abstract}
The Japan Space Exploration Agency Kyoto and Carbon $(K \& C)$ Initiative seeks to demonstrate the potential of the Advanced Land Observing Satellite (ALOS) Phased Arrayed L-band Synthetic Aperture Radar (PALSAR) data for addressing regional applications relating to climate change, carbon cycle science, and environmental conservation. This paper outlines the generation of a regional dual-polarization (HH and HV) mosaic for the entire African continent at spatial resolution on the order of $100 \mathrm{~m}$. The main computational and radar science issues undertaken to generate a seamless mosaic with good radiometric and geometric accuracy are summarized. Preliminary investigations into the thematic information provided by the $\mathrm{K} \& \mathrm{C}$ Africa mosaic and comparisons with the JERS-1 SAR mosaic generated as part of the Global Rain Forest Mapping Project are reported, with emphasis placed on characterizing and detecting change in forests and savannas.
\end{abstract}

Index Terms-Continental-scale radar mapping, Phased-Array L-Band Synthetic Aperture Radar (PALSAR), synthetic aperture radar (SAR) mosaic processing, vegetation monitoring.

\section{INTRODUCTION}

$\mathbf{T}$ HE KYOTO and Carbon (K\&C) Initiative [1], [2] is an international collaborative project of the Japan Aerospace Exploration Agency (JAXA) which aims to support terrestrial carbon science, environmental conservation, and related international conventions through provision of global systematic observations of Phased Array L-band Synthetic Aperture Radar (PALSAR) aboard the Advanced Land Observing Satellite (ALOS) [3], [4]. A key component of the K\&C Initiative is to generate mosaics from hundreds of ALOS PALSAR orbits and to derive thematic information that is spatially consistent over very large areas and for a similar time frame.

In this paper, we report on our experience gained in developing a wide-area PALSAR mosaic over the entire African

Manuscript received September 30, 2010; revised March 22, 2011; accepted July 31, 2011. Date of current version September 28, 2011

G. De Grandi and A. Bouvet are with the DG Joint Research Center, European Commission, 21027 Ispra (VA), Italy (e-mail: frank.de-grandi@ jrc.ec.europa.eu; Alexandre.Bouvet@jrc.ec.europa.eu)

R. M. Lucas is with the Institute of Geography and Earth Sciences, Aberystwyth University, SY23 3DB Aberystwyth, U.K. (e-mail: rml@aber.ac.uk).

M. Shimada is with the Earth Observation Research Center, Japan Aerospace Exploration Agency, Tsukuba 305-8505, Japan (e-mail: shimada. masanobu@jaxa.jp).

S. Monaco is with sarmap SA, 6989 Purasca, Switzerland (e-mail: smonaco@sarmap.ch).

A. Rosenqvist is with solo Earth Observation (soloEO), Tokyo 104-0054, Japan (e-mail: ake.rosenqvist@gmail.com).

Color versions of one or more of the figures in this paper are available online at http://ieeexplore.ieee.org.

Digital Object Identifier 10.1109/TGRS.2011.2165288

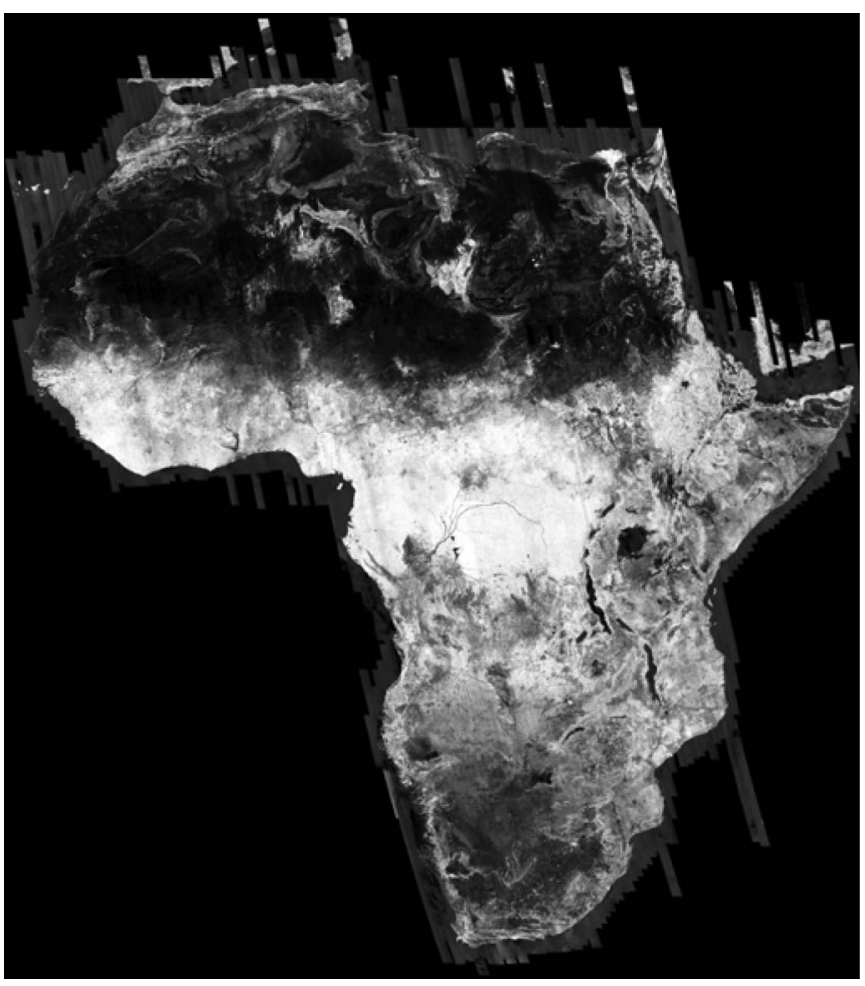

Fig. 1. K\&C continental-scale Africa mosaic. The mosaic was assembled from PALSAR fine-beam dual-polarization (FBD) images (HH band shown), which were geocoded using a latitude-longitude geographic unprojected coordinate system with a pixel spacing of $0.8333 \mathrm{mdeg}$ (roughly $100 \mathrm{~m}$ at the equator)

continent. A snapshot of the prototype mosaic, which was completed at the time of this writing, is shown in Fig. 1. The mosaic is a dual-band ( $\mathrm{HH}-\mathrm{HV})$ data set referenced to a latitude-longitude coordinate system with pixel spacing of $8.33310^{-4^{\circ}}$ (roughly $100 \mathrm{~m}$ at the equator).

The compilation of large numbers of SAR images into a synoptic view of a wide planetary surface to support studies of global geophysical processes is certainly not new. One of the first-and most spectacular - of such technical endeavors was the mapping of the planet Venus surface by the imaging radar aboard the Magellan spacecraft in 1989 [5]. More akin to the work presented in this paper has been the generation of the Central Africa mosaic of C-band ERS-1 imagery in the framework of a joint European Space Agency and Joint Research Center initiative [6] and mosaics of JAXA JERS-1 SAR data over the whole tropical and boreal forest ecozones of the world, with their generation undertaken through international collaborative projects [7]-[11]. These projects were indeed the 
precursors of the $\mathrm{K} \& \mathrm{C}$ Initiative, and they set the stage for building the technical know-how required for the development and analysis of wide-area medium $(<100 \mathrm{~m})$ spatial resolution radar mosaics. However, the $\mathrm{K} \& \mathrm{C}$ is a further development in the scale of performance-hence complexity-with respect to its precursors because of the availability of the following.

1) Both cross-polarized (HV) and cross-polarized $(\mathrm{HH})$ backscatter data.

2) High-quality digital elevation model (in the form of the Shuttle Radar Topographic Mission (SRTM) DEM) with comparable spatial resolution over the whole mosaic's extent.

3) New type of SAR image product developed by JAXA, based on focusing the raw data along extended segments of the sensor's orbit, which is more convenient for large area coverage [12].

4) Improved sensor performance with respect to radiometric stability and geometric accuracy.

5) Optimized acquisition plan, which guaranteed full coverage of the area of interest (continent) in the shortest time compatible with the sensor's orbital cycle (two months in the case of Africa).

In comparison to the JERS-1 SAR, the availability of the cross-polarized channel increases opportunities for forestrybased applications, including detecting and monitoring deforestation and retrieving biomass. The provision of a high-quality DEM paves the way for the utilization of precision geocoding, radiometric corrections for effects induced by topography and terrain morphology measures as additional training sets in classification procedures. Improving sensor performance and optimizing data acquisition are of paramount importance for the generation of seamless mosaics which, in turn, is a prerequisite for successful thematic exploitation of the data at regional scales.

The large amount of data available for generating wide-area radar mosaics and the improved characteristics of these data call for new approaches to processing and analysis. While the cost of generating the data mosaics is high, this should be weighed against the subsequent benefits in relation to thematic applications at regional or continental scales. For Africa, such applications include the detection of deforestation activity, classification of vegetation types, and retrieval of woody biomass.

This paper provides an overview of how the $\mathrm{K} \& \mathrm{C}$ mosaic of Africa was generated, an assessment of the data set quality, and the preliminary observations relating to the richness in information content and potential for future thematic applications. In Section II, the bespoke processing chain designed for generating the mosaic is outlined, and the main processing issues which arose in the implementation phase are discussed. In Section III, the effects of seasonality (and particularly on soil and vegetation moisture) on radiometry and vegetation cover are considered, and their possible causes in terms of underlying scattering physics are discussed with reference to passive microwave measurements. In Section IV, some preliminary thematic observations obtained mainly by visual inspection are made. The conclusion and recommendations for this paper are provided in Section V.

\section{Processing Issues}

\section{A. Mosaic Processing Chain}

The K\&C PALSAR raw data used to generate the mosaic were acquired in 2007 and focused by JAXA using a proprietary SAR processor (SigmaSAR). The processor generates path images in slant range, amplitude data at two polarizations $(\mathrm{HH}$ and HV; with 16 looks in azimuth and 4 looks in range), a pixel spacing of $37.5 \mathrm{~m}$ in range and $50.67 \mathrm{~m}$ in azimuth, and an image size corresponding to approximately $70 \mathrm{~km}$ in range (ground) and up to 2000-3000 km in cross-range.

A number of features of the $\mathrm{K} \& \mathrm{C}$ path data (i.e., large volumes, nonlinear geometry, and radiometric anomalies) required the development of dedicated processing chains for the assemblage of wide-area mosaics of acceptable geometric and radiometric quality. For this purpose, a number of algorithms for geometrically and radiometrically revising and combining path image assembly were developed and implemented.

The functionalities implemented in the $\mathrm{K} \& \mathrm{C}$ Africa mosaicking software include the following.

1) Housekeeping routines to handle the ingestion and the file structure of the JAXA path image data sets.

2) Adaptive calibration revision of the original slant range data sets. This module automatically checks for the presence of radiometric anomalies and accordingly calibrates the data (see Section II-B)

3) Extraction of subsets corresponding to the geographical extent of each projected strip image from the SRTM continent-wide DEM [13] generated for Africa.

4) Geocoding into a geographic reference coordinate system (e.g., unprojected latitude-longitude) using the solution of the range-Doppler equations. This step also produces auxiliary data containing the effective local incidence angles for each pixel of the backscatter amplitude image (see Section II-E)

5) Compression/decompression of the geocoded imagery to optimize data volume and processing time.

6) Assemblage of the geocoded strips within a geographic bounding box. The module uses an interstrip amplitude blending algorithm to avoid edge effects.

7) Radiometric revision of the mosaic to correct for seasonality effects and residual calibration errors, with this based on the estimation of backscatter differences along overlapping borders of neighboring strips (see Section II-D).

The special-purpose modules are interfaced through a batch processor to the underpinning functions (e.g., geocoding) provided by the commercially available software SARscape [15]. In this way, large batches of data could be processed in the background, with the operator's intervention then limited to some critical steps such as revision of the mosaic's calibration. Indeed, optimization of processing resources (memory and disc space) and processing time was one of the challenges posed by the construction of the medium spatial resolution continentalscale data set.

In the following sections and in connection with the characteristics of the data used to generate the Africa mosaic, the main 


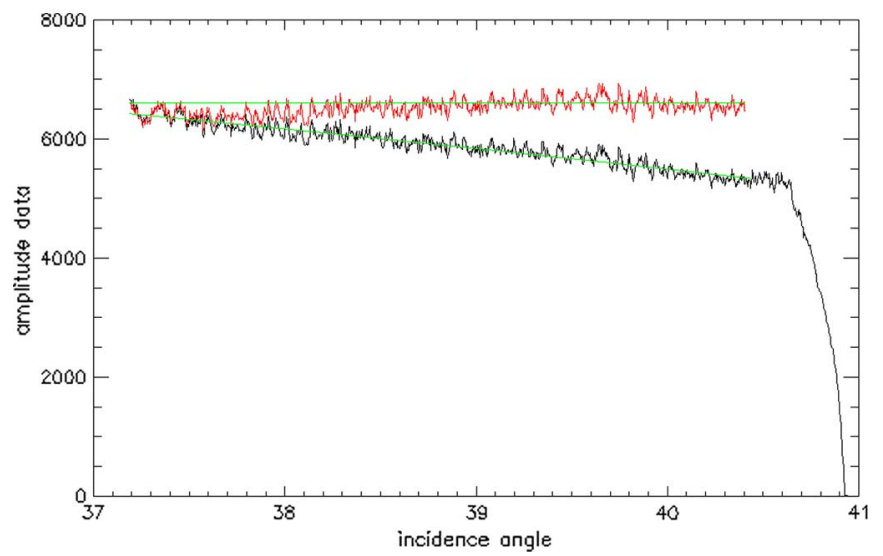

Fig. 2. Range profile as a function of incidence angle, showing the power loss at the end of swath and the linear negative trend within the swath (black line in graph). The red line shows the corrected profile after the adaptive calibration procedure, which is based on linear fitting of the most homogeneous blockaveraged (in azimuth) range profiles (linear fitting function in green).

issues that had to be resolved in the design and implementation of the processing chain are described in more detail.

\section{B. Radiometric Revision of Path Slant Range Images}

Insight into the radiometric fidelity of the $\mathrm{K} \& \mathrm{C}$ path data sets can be gained by considering average slant range profiles. The profiles are computed by selecting areas which are as homogeneous as possible in terms of the illuminated target from near to far range. An example is shown in Fig. 2. The related data set is KC_004-13611N17S10FBDSLT1 (according to JAXA file naming convention) at $\mathrm{HH}$ polarization. The range (black line) and corrected profiles (red line) were extracted from a block of 512 lines (amplitude slant range data) bracketing an area of homogeneous dense tropical forest extending from near to far range. On close inspection, two features are strikingly evident: a linear negative trend of the amplitude signal from near to far range and an abrupt almost complete loss of power at the end of the swath. Quantitatively, the power ratio between the near and far ranges is approximately $-2 \mathrm{~dB}$. This amount of power loss cannot be justified either by the dependence on ground scattering area or by the radar cross section on incidence angle. In the first case, assuming that the data provided by JAXA are proportional to power per unit area in slant range $\beta_{0}$, the power ratio for the range of incidence angles in this data set should be roughly $-0.04 \mathrm{~dB}$. In the second case, wave scattering modeling of the dense tropical forest indicates that the power ratio at $\mathrm{HH}$ due to dependence of the radar cross section on incidence angle should be on the order of $-0.13 \mathrm{~dB}$. Similar considerations apply for areas dominated by surface scattering (e.g., bare soil and water).

This analysis suggests that two radiometric anomalies affect the data and should be taken into consideration in a revision process: 1) a complete loss of signal at image margin in range direction and 2) a linear signal drop from near to far range within the segment with a valid signal. However, the problem is compounded by the fact that such anomalies are not observed systematically and consistently throughout the data sets used in the compilation of the mosaics. The abrupt power drop sometimes happens at far range, at near range, or even both (presumably as a function of latitude in the geographic position of the strip image). The linear negative trend in range is not consistent in terms of the rate of decay throughout data sets and, within the same set, depends on average backscatter. Moreover, in many cases, the anomaly is not present at all.

This scenario strongly suggests that the radiometric revision process of the $\mathrm{K} \& \mathrm{C}$ strip data cannot be based on theoretical global correction functions, even if parameterized by free variables, but must, per force, rely on an adaptive algorithm driven by local estimation of the radiometric trends and anomalies. The basic assumptions underlying the algorithm are the following.

1) The negative linear trend in range is system induced by a multiplicative gain function such that

$$
g(r)=g(0)+m \times r
$$

where $r$ is the range coordinate (pixel index in the column direction of the slant range data) and $m$ and $g(0)$ are the parameters of the linear fit. This function can be estimated from averaged range profiles in homogeneous regions. Homogeneous regions are defined as along-track blocks (consecutive image lines) where targets with similar and constant radar reflectivities are present at near and far ranges. The best candidate region for the range profile estimation is searched by dividing the strip image into along-track segments and by selecting the one where two conditions are verified: minimum global backscatter variance and normalized difference between mean backscatter values at near and far ranges less than $10 \%$. The range profile is fitted linearly, and a correction multiplicative function is defined as

$$
c(r)=1-\frac{m \times r}{g(0)} .
$$

2) In the same data set, the rate of decay of the linear trend (if present) can be characterized by two functions, namely, $g_{1}(r)$ and $g_{2}(r)$, corresponding (in a loose sense) to areas dominated by volume scattering (e.g., forests and woodlands) and surface scattering (e.g., bare soil and sparse vegetation) respectively. These areas can be identified by segmenting the range of backscatter values in the data set into two classes: high and low backscatters. Specific threshold values for identifying the two classes must be chosen as a function of the polarization. The two-class segments are disjoint. Therefore, the region in-between is characterized by a continuous functional $F\left(g_{1}, g_{2}\right)$ of the two functions $g_{1}$ and $g_{2}$.

In a nutshell, the algorithm is composed of the following three steps.

1) The detection and removal of the power drop at the data set margins.

2) The estimation of the linear power trend in range by a search of the most homogeneous block and for two backscatter classes (a proxy for volume and surface scattering). 


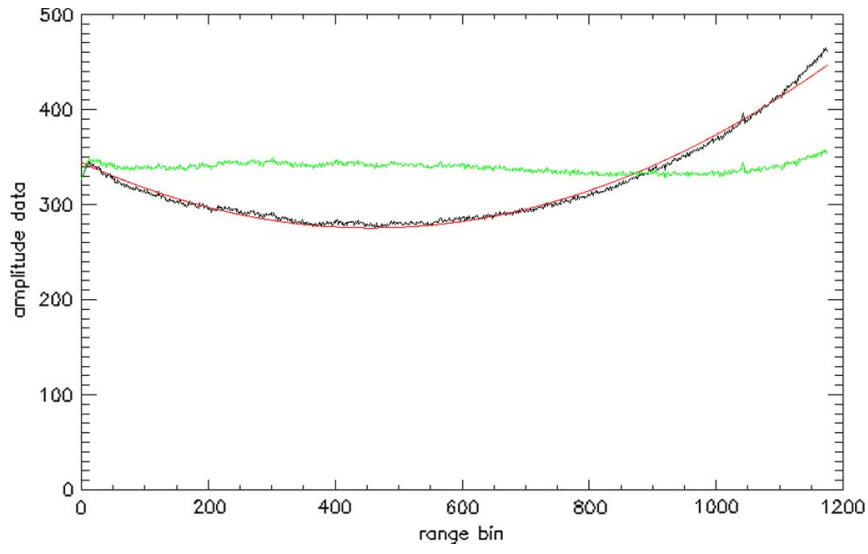

Fig. 3. Range profile of an FBD (slant range) HV data set estimated in a block corresponding to a homogeneous (along the full swath) target featuring low backscatter. The corresponding average backscattering coefficient $\sigma^{0}$ is on the order of the noise equivalent backscattering coefficient ( $-29 \mathrm{~dB})$. The impact of system thermal noise (generated by electron conduction in the system) becomes relevant and results in a nonlinear increasing trend in intensity data (black line in the graph). An empirical additive correction function is derived by polynomial fitting of this range profile (red line), and it is applied to calibrate all $\mathrm{HV}$ data sets. The green line shows the same range profile after the correction for thermal noise.

3) The application of an inverse gain function based on the estimated trends.

The automatic calibration procedure reports an error status when a homogeneous region cannot be detected. In this case, the range profile is evaluated by a manual procedure based on the search of the best homogeneous block by visual inspection of the strip image. In practice, only a few such cases occurred during the mosaic processing.

\section{Thermal Noise}

The noise equivalent $\sigma^{0}$ (NES) for PALSAR dual-pol imagery is rated at $-29 \mathrm{~dB}$. In some desert areas of Northern Africa, the response at cross-polarization falls below such a figure. Therefore, the contribution of thermal noise becomes noticeable in areas of low backscatter and is dependent on the incidence angle. The theoretical noise floor is a nonlinear function of the antenna pattern, the range distance, and the incidence angle [16]. In our approach, the additive noise component was estimated using an empirical method based on a second-degree polynomial fitting of a range intensity profile measured over a homogeneous (from near to far range) area with a backscatter coefficient lower than the NES and assumed constant throughout the swath. The estimated additive noise component was then used to compensate the trend in range of all HV data sets. A typical range profile corresponding to a dark area before and after the correction is shown in Fig. 3.

\section{Radiometric Interstrip Mosaic Balancing}

Within the mosaic compiled from the geocoded and range calibrated strips, radiometric discontinuities between strips were evident. In particular, differences in backscatter values between strips were on the order of $2 \mathrm{~dB}$ (see Fig. 4). Such discontinuities were related to seasonality and local weather

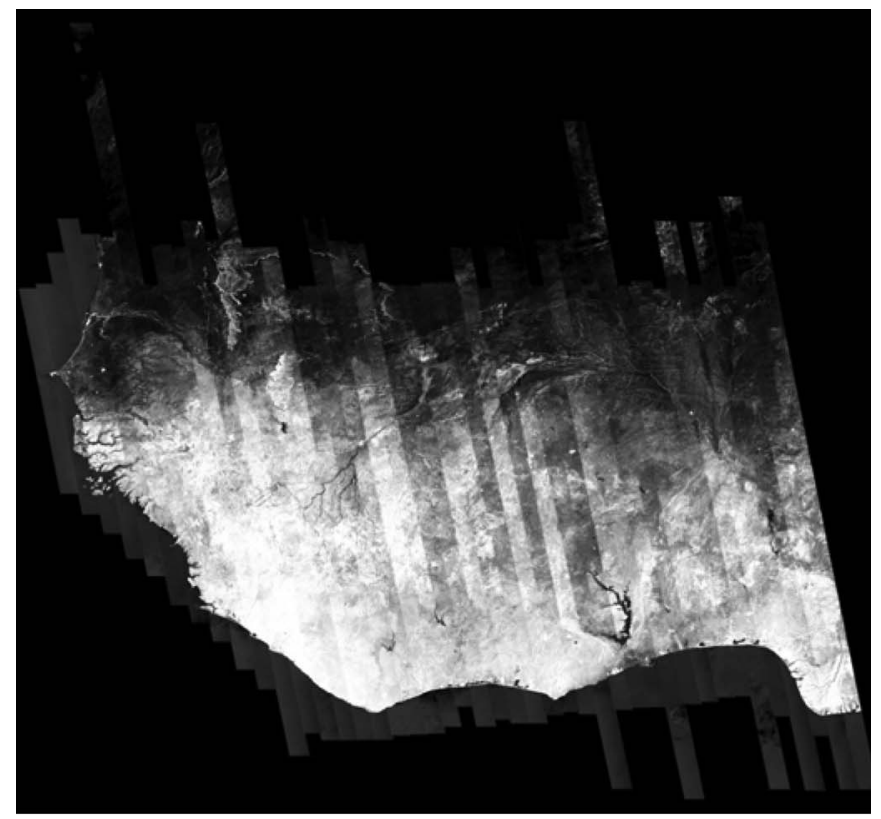

(a)

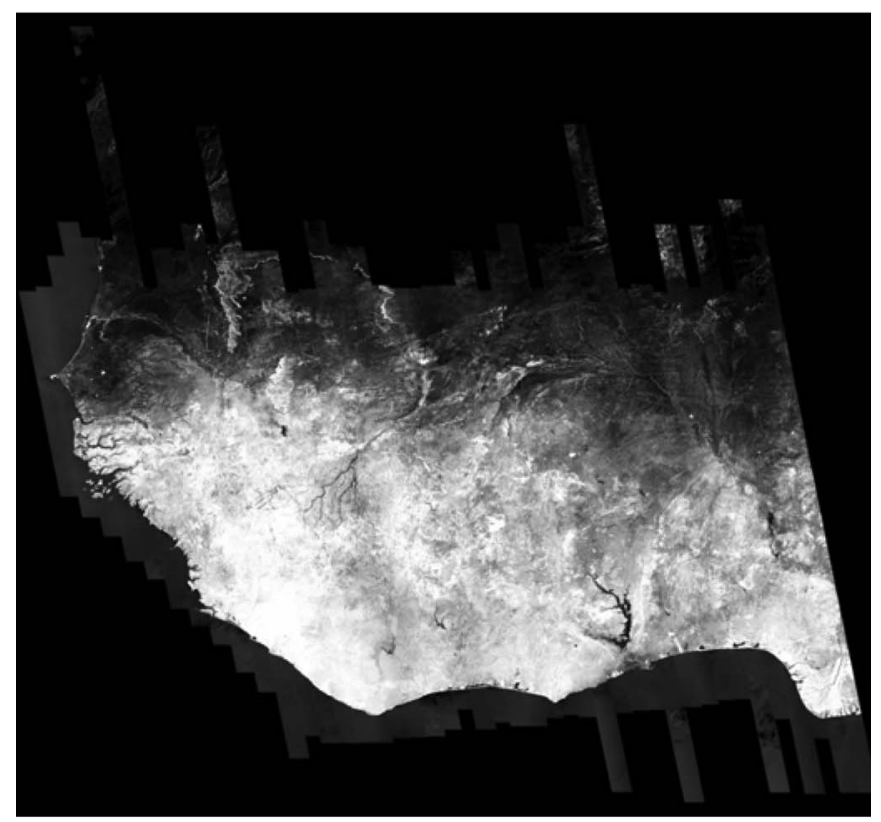

(b)

Fig. 4. West Africa part of the mosaic. Relevant radiometric differences (on the order of $2 \mathrm{~dB}$ ) are clearly visible between adjacent strips in the (a) original (uncorrected) mosaic. The mosaic after radiometric balancing, based on interstrip discrepancy measures, is shown in (b).

conditions, as documented in Section III. Indeed, to assure spatial continuity, part of the 2007 acquisitions corresponding to the dry season within tropical Central Africa was necessarily complemented with acquisitions during the wet season. This difference in acquisition time can account for differences in radar reflectivity because of the evolution of the target's properties (e.g., change in vegetation cover or soil and vegetation moisture).

In the overlap area between two adjacent strips, the same target on the ground is seen by the radar with a different incident angle (far and near ranges). Assuming a cosine law for the radar cross section dependence on incidence angle, the difference in 
backscatter due to the near-far range incidence angle difference is roughly $0.78 \mathrm{~dB}$ and is on the order of the PALSAR radiometric accuracy. However, this figure in decibels corresponds to a power DN ratio of 1.196 , which would still result in visible edge effects in the imagery. Other minor interstrip unbalancing is produced by residual errors in range calibration.

For this reason, the first approximation mosaic needs to be corrected to arrive at a more radiometrically homogeneous version, which could be suitable for successive automatic interpretation or the retrieval of biophysical parameters (e.g., forest biomass). This correction is achieved by an interstrip balancing algorithm which relies on information derived by along-track profiles of the backscatter values estimated within the area of overlap between one strip and those surrounding.

Since the radiometric discrepancies depend on the position within the strip (land cover and conditions), it was not possible to define a global stripwise gain factor. Therefore, a gain function was defined for each strip which depended linearly on the column coordinate (approximate range direction) of the strip frame and was a piecewise linear approximation along the line coordinate (along-track direction) of the ratio between the strip border profile and the corresponding profiles of the neighboring strips. A strip frame was defined as the area where values were available in the geocoded image. Thus, calling $P_{k}^{\text {left }}(i)$ and $P_{k}^{\text {right }}(i)$ estimates of the mean DN values along the left and right borders at position $i$ along track of strip $k$ and $P_{k-1}^{\text {right }}(i)$ and $P_{k+1}^{\text {left }}(i)$ estimates of the corresponding profiles of adjacent strips at the left and right of strip $k$, we define the discrepancy measures as

$$
\begin{aligned}
D^{\text {left }}(i) & =\frac{P_{k-1}^{\text {right }}(i)}{P_{k}^{\text {left }}(i)} \\
D^{\text {right }}(i) & =\frac{P_{k+1}^{\text {left }}(i)}{P_{k}^{\text {right }}(i)} .
\end{aligned}
$$

An example of the discrepancy measure and the related gain function is shown in Fig. 5. These discrepancy measures formed the basis for the mosaic correction algorithm. As the first step, the measures $D(i)$ were used to locate the strips affected by large radiometric discrepancies. For this purpose, the mode of the distribution (density function) of $D^{\text {left }}$ and $D^{\text {right }}$ was computed. This figure of maximum discrepancy between adjacent strips was further screened by an operator and used to flag the strips as anomalous. Automatic detection of anomalous strips was difficult because the eventual occurrence in the same mosaic of strips with higher and lower than normal DN values led to ambiguities in the discrepancy measures.

Once the anomalous strips had been flagged, the algorithm proceeded according to the following principle. Gain functions were defined for the anomalous strips using $D^{\text {left }}(i)$ and $D^{\text {right }}(i)$ measures with respect to normal adjacent strips. In the event that a second anomalous strip was present near to the first, then the gain function was computed from the only available measure (left or right) and assumed constant in range. This approach limited the possible number of consecutive anomalous strips to two. Indeed, this condition was satisfied in the processing of the whole Africa mosaic.

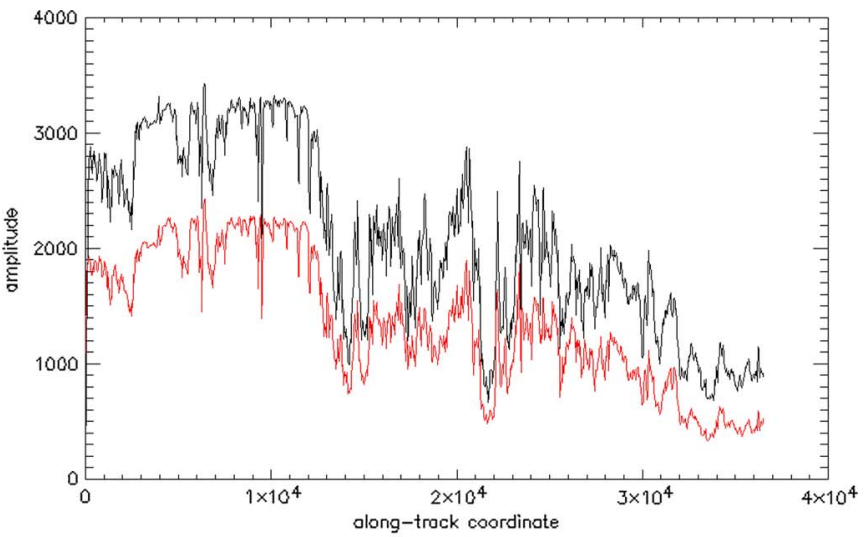

(a)

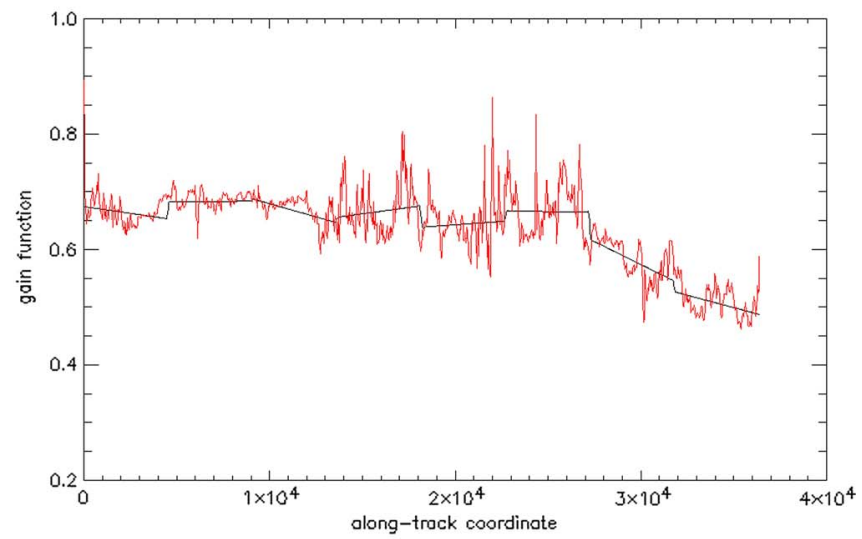

(b)

Fig. 5. Profiles in the along-track direction of mean DN values within the overlap area at the margin between two adjacent strips (the black line is the first strip profile, and the red line is the overlapping second strip profile in graph a). The radiometric differences are not constant along track, which is a fact that suggests the use of a variable gain function. This gain function is estimated by a piecewise linear fitting of a smoothed version of the ratio between the two along-track profiles (red line in graph b). The segments in black are the gain function resulting from the piecewise linear fitting algorithm.

These gain functions balanced the radiometry of the anomalous strips to match that of adjacent strips. Next, the residual trends in range calibration and other minor interstrip unbalances were corrected by sharing the correction weight between the neighboring strips (moving the trend half way up and half way down). In this way, the propagation of errors was avoided. In more detail, the mosaic balancing algorithm is comprised of the following steps.

1) Construction of a data structure that held information on the neighbors of each strip. This was achieved by assigning each strip position in the mosaic's canvas with a unique identifier.

2) Computation, for each geocoded strip $k$, of profiles $P_{k}$ and discrepancy measures $D_{k}$. Since one strip can have several neighbors at the left or right, a data structure ID was also generated, which kept track of the neighbor for each value of the profile and how the line coordinates of the two strips were related. Thus, $P_{k}(i) \Leftrightarrow I D(i)$. The structure ID was used when a discrepancy measure needed to be updated (e.g., where an anomalous strip was corrected by a gain function). This was the only step that required ingestion of the actual strip data sets. 
3) Discrepancy analysis and choice of the anomalous strips based on an interactive procedure.

4) Generation of gain functions for the correction of anomalous strips. As explained previously, these functions were derived from the discrepancy measures relative to adjacent normal strips. The gain functions were computed by a piecewise linear fitting of the $D_{k}$ functions. In fact, the $D_{k}$ functions, being ratios of two samples from speckle noise, would introduce artifacts if used as multiplicative factors of the strip amplitude data. The $D_{k}$ functions were first low-pass filtered and downsampled by a factor of 64 to obtain a slow-varying trend. This trend function was then approximated by a piecewise linear function by an iterative algorithm. At each step of the iteration, the trend function was split into an increasing number of consecutive segments by halving the length of each segment. Each segment was fitted linearly, and the global root mean square (rms) differences between the trend function and the piecewise linear approximation were computed. The procedure was halted when the rms differences between two successive iterations increased or a predefined maximum number of divisions was reached. The piecewise linear trend was then upsampled to the original resolution by spline interpolation. The gain functions for anomalous strips were stored as vectors in files to be used later by the mosaicking procedure and in the compilation of the second approximation revised mosaic.

5) Upgrade the profiles $P_{k}$ of the anomalous strips with respect to the gain functions defined in the preceding step, and recompute the discrepancy measures $D_{k}$ which had been affected by a change of $P_{k}$.

6) Generate gain functions for all strips from the $D_{k}$ functions as

$$
\begin{aligned}
g_{k}^{\text {left }}(i) & =\frac{1}{2} \operatorname{LININTERP}\left(D_{k}^{\text {left }}(i)\right)+\frac{1}{2} \\
g_{k}^{\text {right }}(i) & =\frac{1}{2} \operatorname{LININTERP}\left(D_{k}^{\text {right }}(i)\right)+\frac{1}{2} .
\end{aligned}
$$

The gain function used by the mosaicking procedure for mosaic balancing was finally

$$
g_{k}(i, j)=\frac{g_{k}^{\text {right }}(i)-g_{k}^{\text {left }}(i)}{\Delta j} j+g_{k}^{\text {left }}(i)
$$

The results obtained by the strip balancing algorithms are shown in Fig. 6. Note that the automatic balancing algorithm could introduce local artifacts while still adjusting globally the radiometric balance. This problem can, in particular, be expected when the margin of one strip is corrupted, for instance, by a residual power drop at far range. In this case, the error would propagate to the neighboring strip. Given the extent of the data set, these local artifacts are difficult to evaluate by visual inspection. Manual fine tuning of the mosaic radiometric balancing will be necessary at the stage when continentalscale thematic products will be generated by automatic pattern classification.

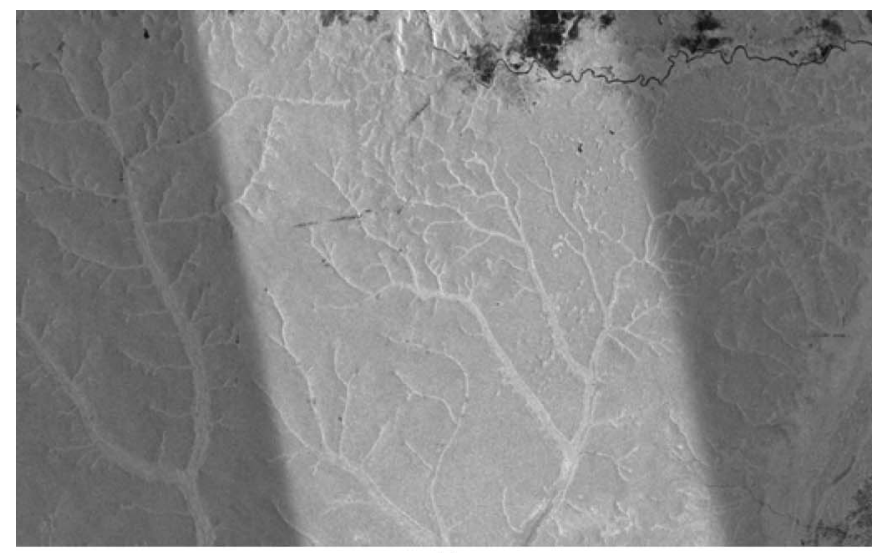

(a)

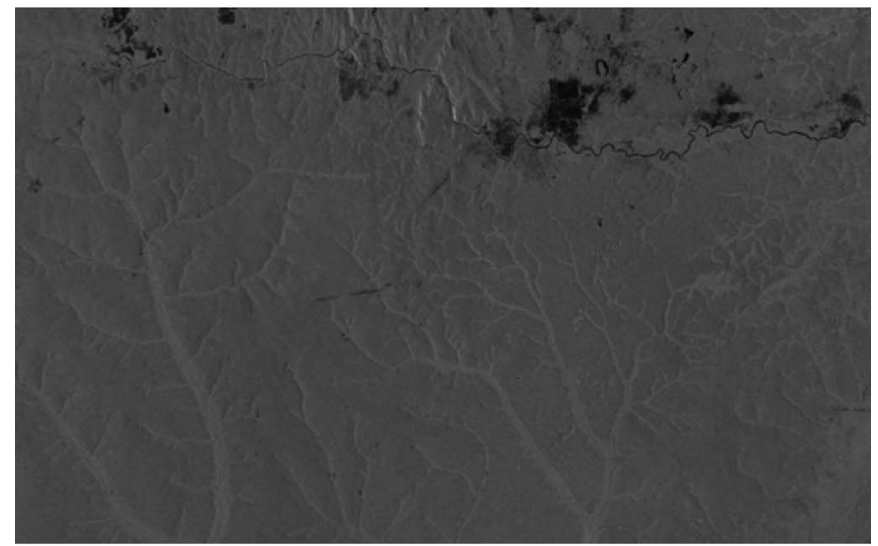

(b)

Fig. 6. Result of the strip balancing algorithm (b) when applied to a set of strips with one radiometric anomaly viz. higher backscattering coefficient (a) possibly due to vegetation water content and soil moisture change (see Section III for related analysis).

\section{E. Geocoding}

Terrain geocoding of the slant range path data sets was performed using a module of the SARscape software [15]. The continent-wide DEM of Africa derived from the SRTM [13] was adopted. This DEM was provided in a geographic projection (latitude/longitude coordinates) using the WGS-84 horizontal datum, with a pixel size of $3^{\prime \prime}$ (i.e., $0.8333 \mathrm{mdeg}$ equating to approximately $100 \mathrm{~m}$ at the equator). The geocoded PALSAR imagery of the Africa mosaic was generated in the same projection and spatial resolution of the DEM. This choice assured the best geometric and radiometric accuracy (see also Section II-F). Moreover, past experience with thematic applications based on the Global Rain Forest Mapping (GRFM) data sets indicated that the adopted pixel spacing was best suited for regional-scale vegetation mapping studies. Higher spatial resolution data are more suited to local-scale applications, such as the detection of selective logging.

The vertical error in the C-band SRTM DEM varies as a function of the physiographical features and the land cover type. For instance, the rms vertical errors reported in the literature are around $5 \mathrm{~m}$ over forested areas and around $3 \mathrm{~m}$ for bare ground and water bodies [14]. However, this range of vertical errors in the DEM would propagate into horizontal displacements on the order of $4.5 \mathrm{~m}$ for the PALSAR observational geometry and 
for elevations up to $1000 \mathrm{~m}$. Since the mosaic was geocoded with a pixel size of approximately $100 \mathrm{~m}$, the variation in DEM vertical error was not considered to be an important error source, and no action was taken to compensate for it.

SARscape geocoding was based on the classical rangeDoppler approach, with this being the only appropriate way to obtain precision geocoding of SAR data. SAR systems cause nonlinear distortions (particularly because of the presence of topography), and unlike in the case of optical data, affine polynomial transformations (which assume a flat earth) are insufficient for converting coordinates into a cartographic reference system.

Mapping from the slant range SAR geometry into a cartographic projection was achieved by considering the parameters of the synthetic aperture imaging. Therefore, the range-Doppler approach called for the solution of the following relations:

$$
\begin{aligned}
\vec{R}_{S} & =\vec{S}-\vec{P} \\
f_{D} & =\frac{2\left(\vec{v}_{p}-\vec{v}_{s}\right) \bullet \vec{R}_{S}}{\lambda\left|R_{S}\right|}
\end{aligned}
$$

where $\vec{S}$ and $\vec{P}$ are the sensor and target position vectors, $\vec{v}_{p}$ $\vec{v}_{s}$ is the velocity of the target relative to the sensor, and $\lambda$ is the wavelength of the carrier.

Geocoding was implemented by a backward solution of the range-Doppler equations. Starting from each point within the DEM reference system, the corresponding point in the slant range radar geometry was found using the range-Doppler equations. Elements from the SAR geometry frame were then resampled into the earth projection (DEM) coordinate system. The JAXA K\&C path products were not processed at zeroDoppler and hence, the proper values of the Doppler centroid had to be used in the solution of (7), with these provided by JAXA in an auxiliary file in the form of a polynomial approximation of the Doppler dependence on slant range distance.

Sources of geometric errors in SAR geocoding propagate from satellite orbit, range time, Doppler frequency and DEM accuracies [17]. In our case, the assessment of the geocoding accuracy was conducted a posteriori by establishing common features within the same DEM used in the geocoding procedure. As such, the measures of accuracy are relative. Difference vectors between control points in the SAR image and reference DEM image were defined through visual inspection, with the maximum difference vector magnitude being $<1$ pixel.

\section{F. Radiometric Correction for Topographic Effects}

SAR radiometry is affected by topography due to changes of the ground scattering area and local incidence angle, which, in turn, has an impact on the backscattering properties of the targets. Correction of these effects is important if the data are to be used in automatic classification [18], [19]. On the other hand, such corrections tend to smooth features related to terrain morphology and render the data set less amenable to visual interpretation by the expert, at least for certain thematic applications. Therefore, in our implementation, radiometric normalizations for topography were applied a posteriori.

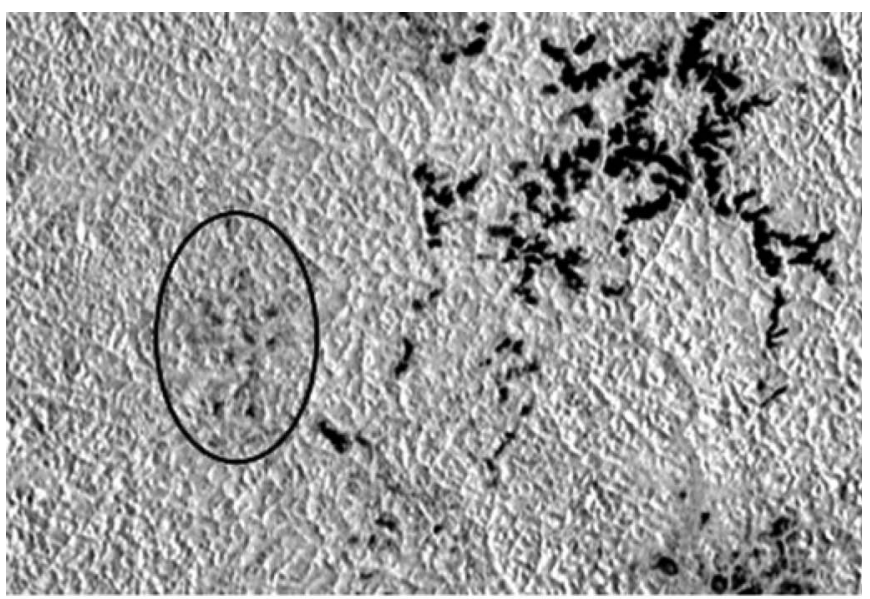

(a)

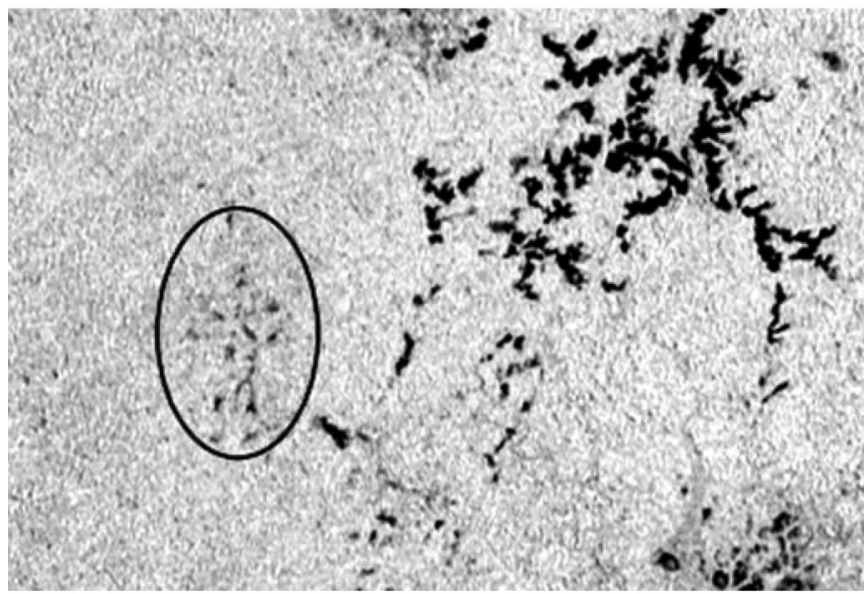

(b)

Fig. 7. Effect of the radiometric correction for topographic effects portrayed in a scene at the border between the Democratic Republic of Congo and Gabon, featuring moderate relief. The images are a composite of $\mathrm{HH}-\mathrm{HV}-\mathrm{HH}$ PALSAR mosaic amplitude data.

The normalization entailed two corrections, with these accounting for the effective scattering area and radar cross section dependence on local incidence angle. The effective ground scattering area $A_{\text {slope }}$ was obtained by projecting the pixel area in slant geometry to the corresponding tilted terrain surface, as derived by finite differences of DEM adjacent values

$$
A_{\text {slope }}=\frac{r_{a} r_{s}}{\sin \theta_{\text {loc }}}
$$

where $\theta_{\text {loc }}$ is the SAR local incidence angle (i.e., the angle between the incident electromagnetic wave vector $\vec{d}$ and the normal at the terrain surface $\vec{n}$ ). In our case, $\vec{n}$ was derived directly from the DEM at each pixel $(x, y)$ by calculating the cross-product of the two 3-D vectors formed by the adjacent pixels in longitude and latitude, respectively

$$
\vec{n}=\vec{v}_{1} \wedge \vec{v}_{2} .
$$

These two vectors are given by

$$
\vec{v}_{1}=\left(\begin{array}{c}
2 \cdot p_{m} \\
0 \\
H_{x+1, y}-H_{x-1, y}
\end{array}\right) \quad \vec{v}_{2}=\left(\begin{array}{c}
0 \\
2 \cdot p_{m} \\
H_{x, y-1}-H_{x, y+1}
\end{array}\right)
$$



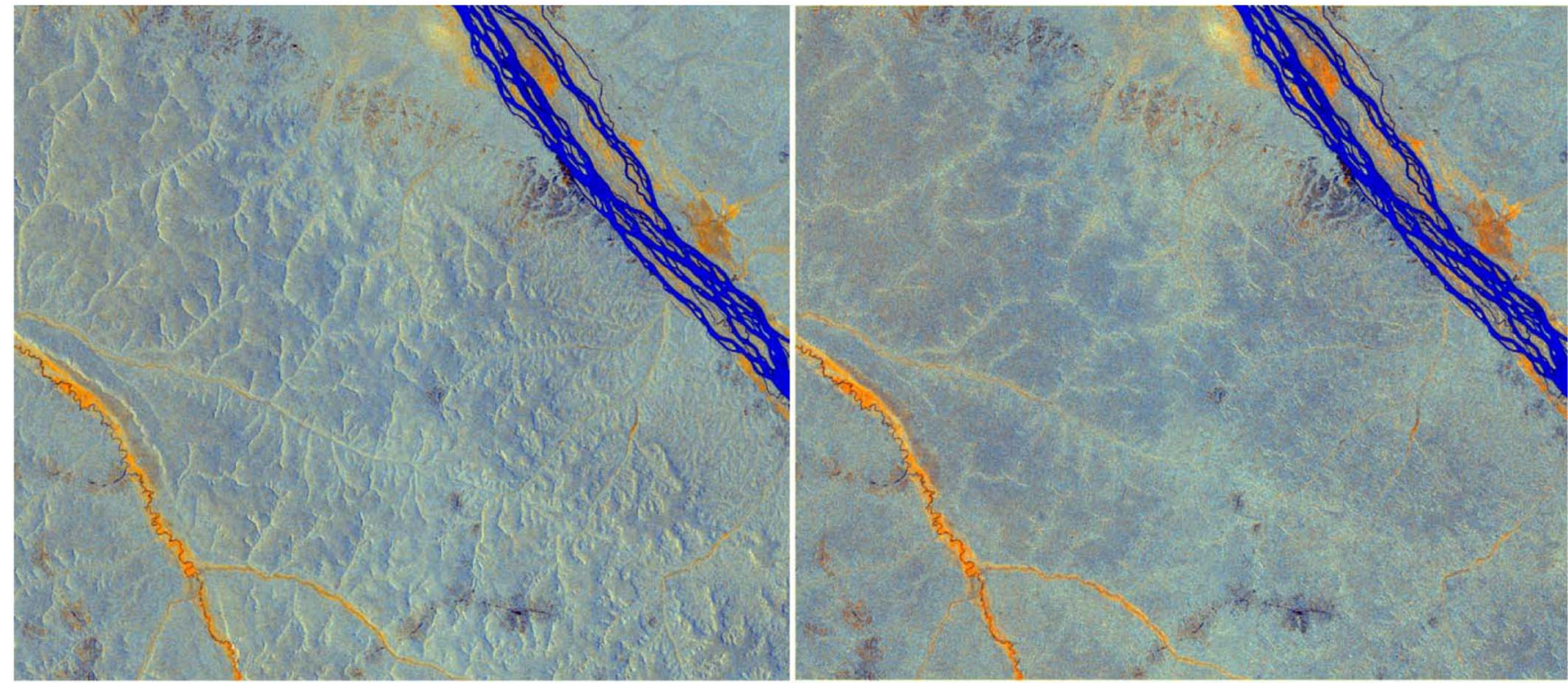

a

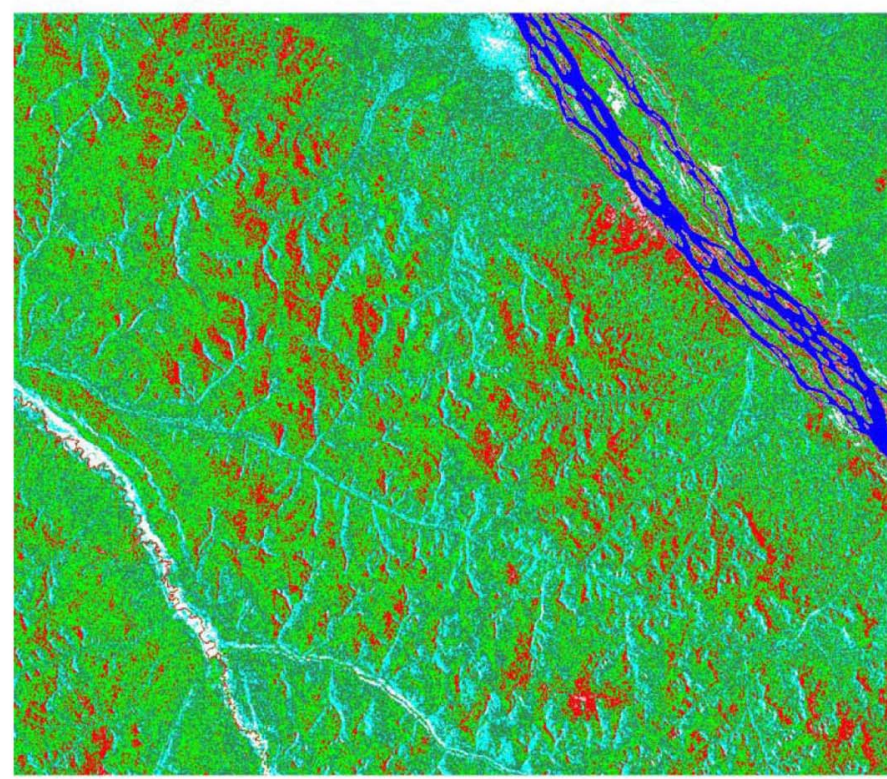

$\mathrm{c}$ b

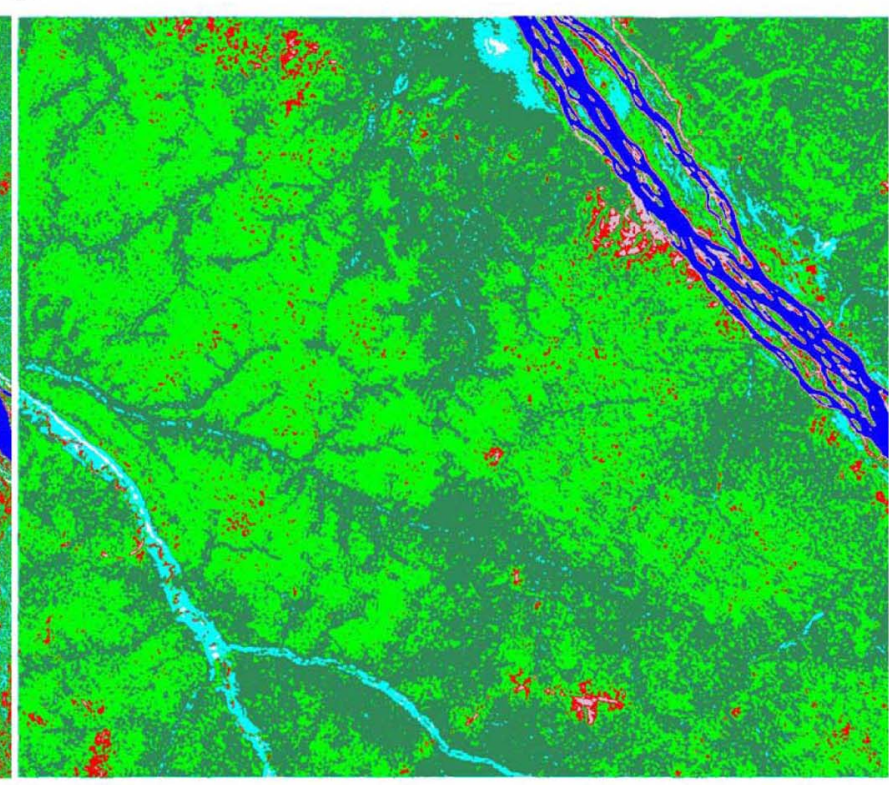

d

\begin{tabular}{|c|c|c|c|c|c|}
\hline water & & "highland" forest & & non-forest1 \\
\hline & flooded forest & & "lowland" forest & & non-forest2
\end{tabular}

Fig. 8. Subset of the mosaic (RGB channels HH, HV, and HV/HH) portraying an area in the Democratic Republic of Congo (a) before and (b) after topographic correction. K-means unsupervised clustering and supervised class labeling were applied to this data set to test the impact of the radiometric corrections on the classification accuracy. Classification from the original data in (c) and from the corrected data in (d).

where $p_{m}$ represents the pixel size in meters and $H_{x, y}$ is the altitude of the terrain at pixel $(x, y)$ as given by the DEM. Finally, the correction factor for the effective scattering area was

$$
C_{\text {area }}=\frac{\sin \theta_{\text {loc }}}{\sin \theta}
$$

where $\theta$ is the nominal incidence angle for flat terrain.
The effect of incidence angle on the backscattering coefficient depends on the nature of the target as well as on the polarization. These effects can be accounted for by the following: 1) Postponing the correction to the classification phase, given that a priori information on the target type at the scale of the whole mosaic will be available from auxiliary data sets (e.g., MODerate resolution Imaging Spectrometer (MODIS) optical data) or 2) Tailoring the correction to one specific thematic application, accepting that this may be suboptimal for 

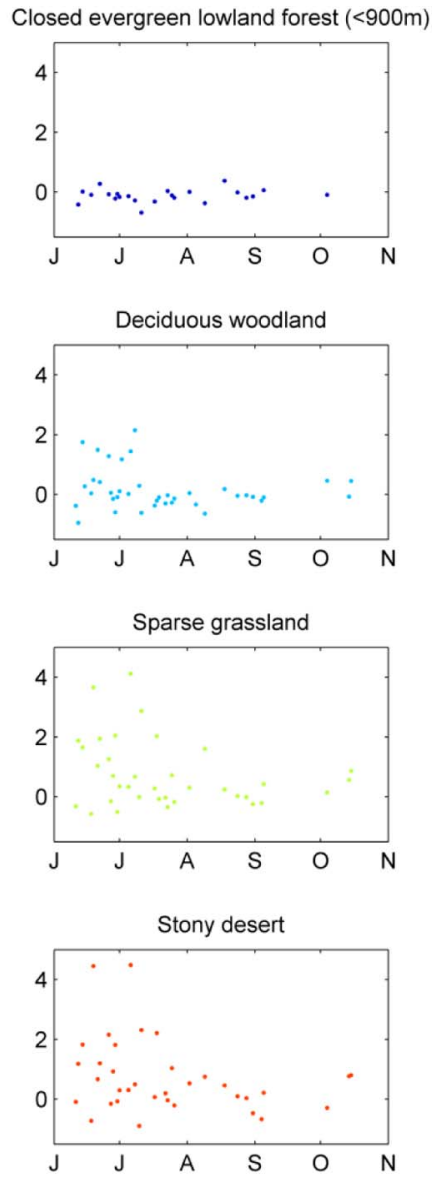
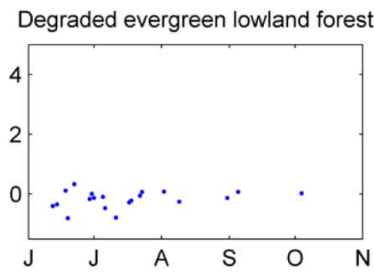

Deciduous shrubland with sparse trees
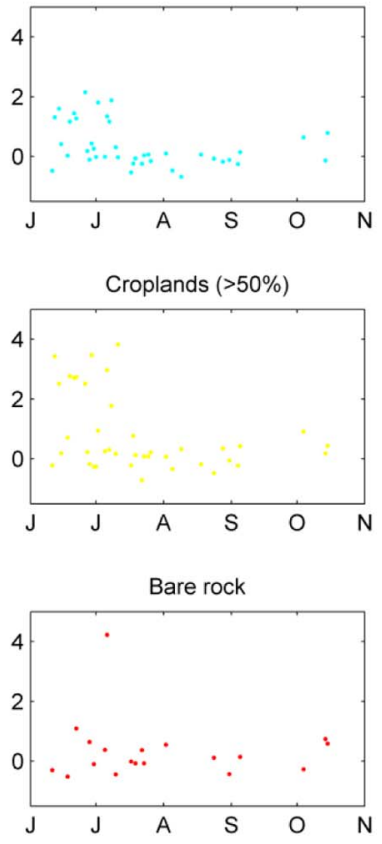
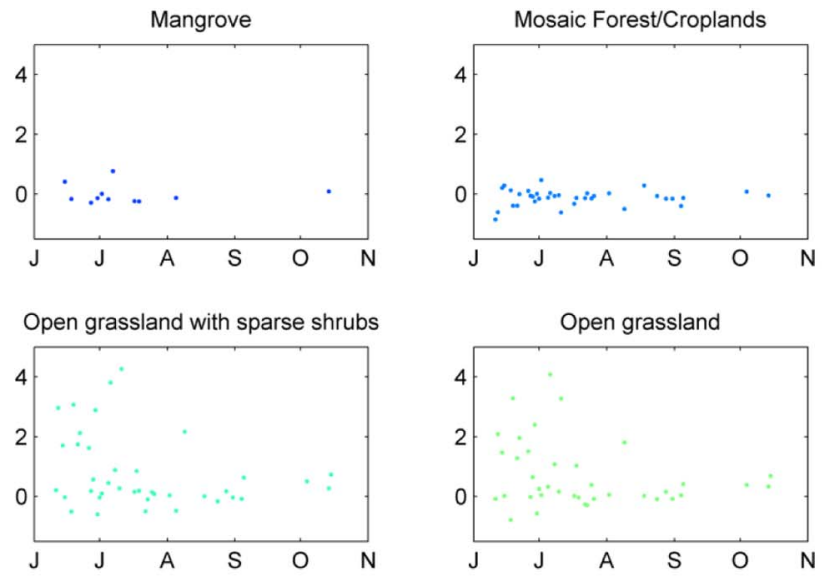

Croplands with open woody vegetation
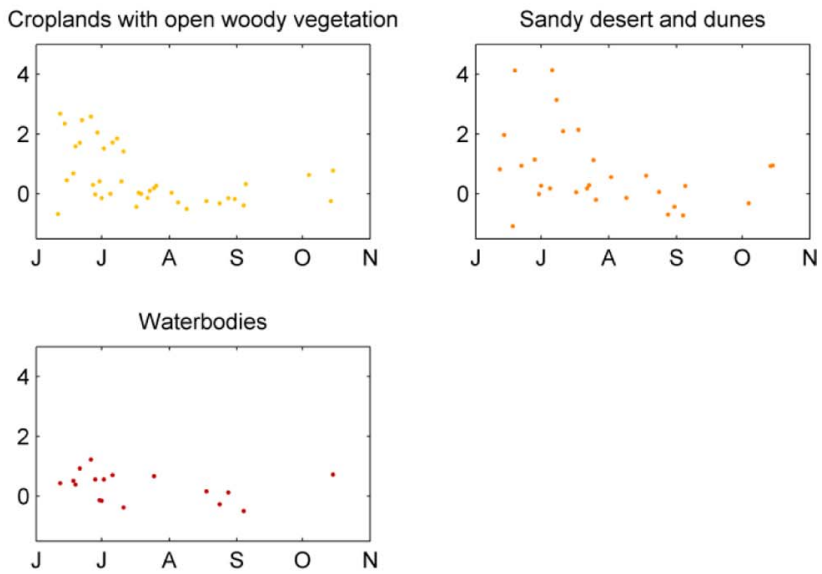

Fig. 9. Radiometric correction (mean difference in decibels between HH intensity after interstrip balancing and HH intensity before interstrip balancing) for each thematic class defined in the global land cover (GLC) map and computed for strip images acquired at different dates. This analysis indicates how different land-cover classes are affected by strip balancing. For dense vegetation (forest), there is almost no correction (the ground is not reached by radiation; therefore, moisture does not affect backscatter), while for more open vegetation (woodlands, shrublands, and grasslands), there are large corrections (more than $1.5 \mathrm{~dB}$ ), which regard strips acquired mostly from June to mid-July (dry season strips whose intensity need to be increased to match the intensity of adjacent wet season strips).

a general land cover mapping task. In view of our applications of interest (primarily mapping of tropical forest and savanna woodlands where volume scattering is more dominant), the latter correction was applied.

The angular dependence of forest backscatter is quite well represented by a cosine function, which accounts for the modified path length of the wave into the canopy [20]. Therefore, the related correction factor was

$$
C_{\text {angle }}=\frac{\cos \theta}{\cos \theta_{\text {loc }}}
$$

The backscatter coefficient corrected for the overall effect of topography was

$\sigma_{\text {corr }}^{0}(\mathrm{~dB})=20 \log _{10}(D N)+10 \log _{10}\left(\frac{\tan \theta_{\mathrm{loc}}}{\tan \theta}\right)-83 \mathrm{~dB}$.

The cosine law, when applied globally, will introduce a distortion of the intensity values for those land cover classes for which this specific dependence does not apply (e.g., when surface scattering dominates). As a consequence, care must be taken for data analysis based on wave scattering modeling (e.g., biophysical parameter retrieval by model inversion). Data modified by the cosine law are intended for specific thematic applications and supervised class labeling techniques (i.e., when the relative intensity values are used), while for more physically based applications (when the absolute backscatter coefficient is important), the original intensity data, complemented by a local incidence angle map, should be used. A discussion on the merits and problems related to cosine function correction can be found in [21].

The efficacy of the topographic corrections in our thematic context of interest is documented by the following cases. For a small subset of the mosaic on the border between Congo and Gabon (Fig. 7), non-forest areas are more visible in the topographically corrected image (see, for example, the circled area), where the backscatter variation associated with relief distortion is removed. The impact of the topographic correction is also illustrated for the Democratic Republic of Congo (Fig. 8). Here, an unsupervised classification based on K-means clustering has been applied to both uncorrected and corrected $\mathrm{HH}$ and $\mathrm{HV}$ images. Greater consistency in the classification using the latter was obtained. 


\section{SEASOnALity EFFECTS}

Seasonal effects (and particularly the change in soil/ vegetation moisture and vegetation cover from the dry to the wet season) can influence the SAR backscatter [22]. As a consequence, the backscatter can change abruptly from one strip to another, particularly if the acquisition dates are far apart. Such an effect is particularly evident in the west of Africa, where the acquisition dates of PALSAR (June to August 2007) spanned over the dry and wet seasons, with the transition period being around mid-June. Such abrupt changes in radiometry were balanced (see Section II) to obtain a seamless data set suitable for regional-scale land cover classification. Nevertheless, the uncorrected mosaic can provide information on the biophysical properties of the surface in terms of soil/vegetation moisture and surface roughness (e.g., presence of tussock grasses), although this is a topic of further research.

To investigate the effects of surface moisture as a function of surface cover, differences in corrected and uncorrected L-band $\mathrm{HH}$ data at the time of ALOS PALSAR acquisitions (which were more evident compared to L-band HV) are shown in Fig. 9 for a range of land cover types given by the GLC2000 land cover map [23]. Radiometric differences of more than $2 \mathrm{~dB}$ were observed for the more open vegetation types (e.g., wooded savannas) but less for forests. In Fig. 10, a map of the perstrip radiometric discrepancies is shown [Fig. 10(a)] together with the corresponding acquisition date (Fig. 10(b); color coded from August 2007 to June 2008). The map highlights that such effects are most evident in the data acquired from June to mid-July.

Lucas et al. [22] highlighted that the backscatter variation over time was attributed to differences in the moisture content of the soil (surface and subsurface) and vegetation. As with this paper, Advanced Microwave Scanning Radiometer-EOS (AMSR-E) brightness polarization ratio data were obtained for dates corresponding to acquisitions of the ALOS PALSAR data. The microwave polarization difference index (MPDI) is defined as [24], [25]

$$
M P D I=\frac{T_{b v}-T_{b h}}{T_{b v}+T_{b h}}
$$

where $T_{\mathrm{bp}}$ is the brightness temperature at polarization $\mathrm{p}$. At $6.6 \mathrm{GHz}$, the MPDI contains information both on the canopy optical depth and soil dielectric properties through emission. Therefore, a trend in a yearly time series of MPDI can be related to changes in vegetation development and water content, while the residual response, which is more random in time, can be linked to variations in soil moisture (see Fig. 11). As an example, the MPDI has been shown to effectively capture the soil moisture dynamics in the Sahelian region [26].

Preliminary comparisons gave some insight into the cause-effect relation. The anomaly signature (proportional to soil moisture) and the seasonal trend (an indicator of vegetation water content) were mapped for each strip at PALSAR acquisition dates (see Fig. 12). From these data, regions were identified, where the vegetation water content was low with
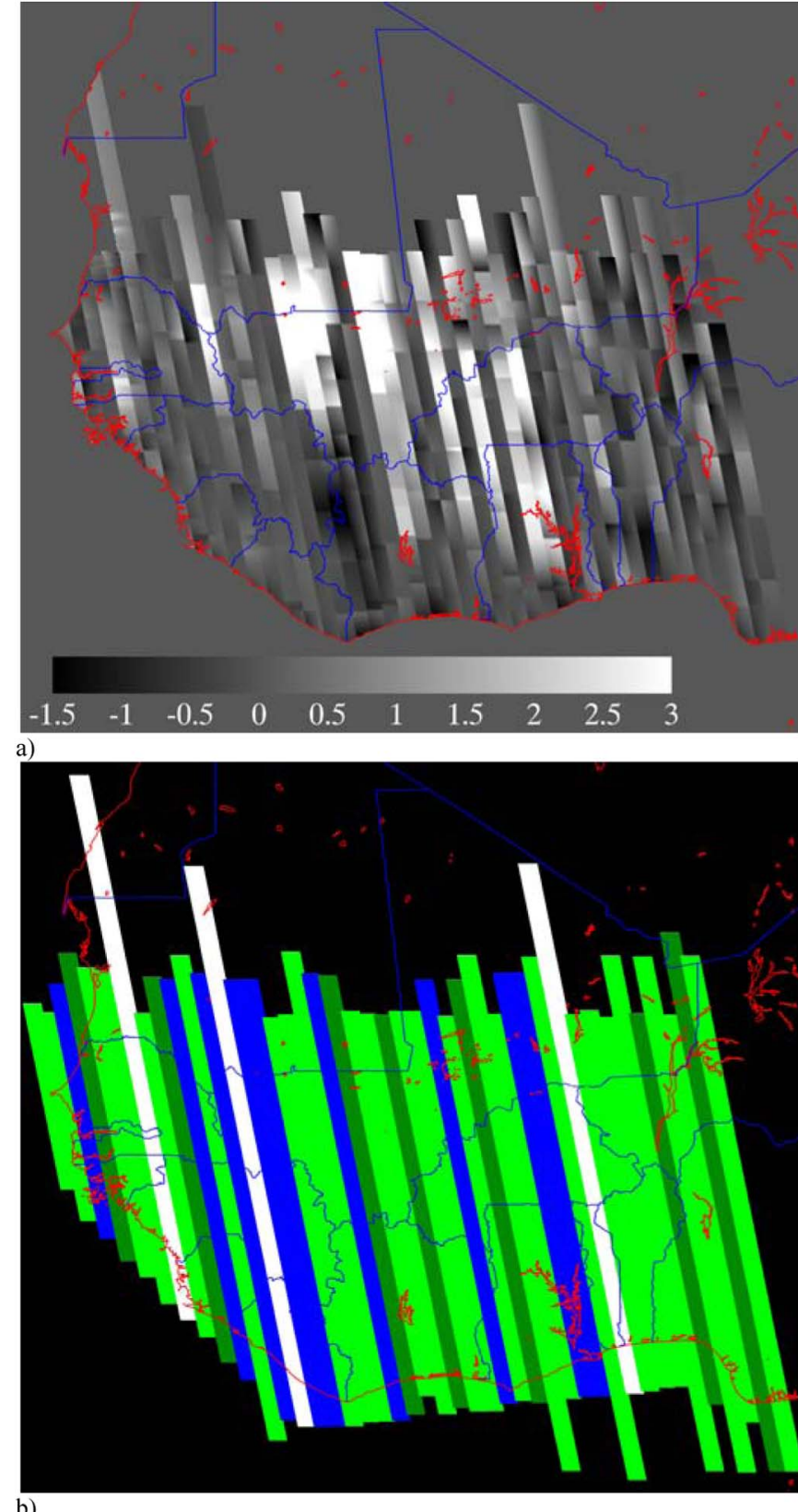

b)

Fig. 10. Map of the radiometric corrections applied to each strip (a) and corresponding acquisition date (b). The dates are color coded: June to midJuly 2007 and 2008 in light green, mid-July to end of July 2007 in dark green, August to September 2007 in blue, and November 2007 in white. This color scheme highlights the fact that large radiometric corrections [white in (a)] concern only the dry season strips (light green) which are surrounded by wet season strips (blue).

respect to the annual mean [red areas in Fig. 13(a)] and where the soil moisture was high with respect to the annual mean [blue areas in Fig. 13(b)]. Assuming a correlation between vegetation water content, soil moisture, and strip image radiometric imbalance, the red areas should correspond to strip images featuring a lower backscattering coefficient and requiring a positive correction, while the blue areas should correspond to strip images requiring a negative radiometric correction. Comparison with the actual radiometric correction map (Fig. 10) suggests the 


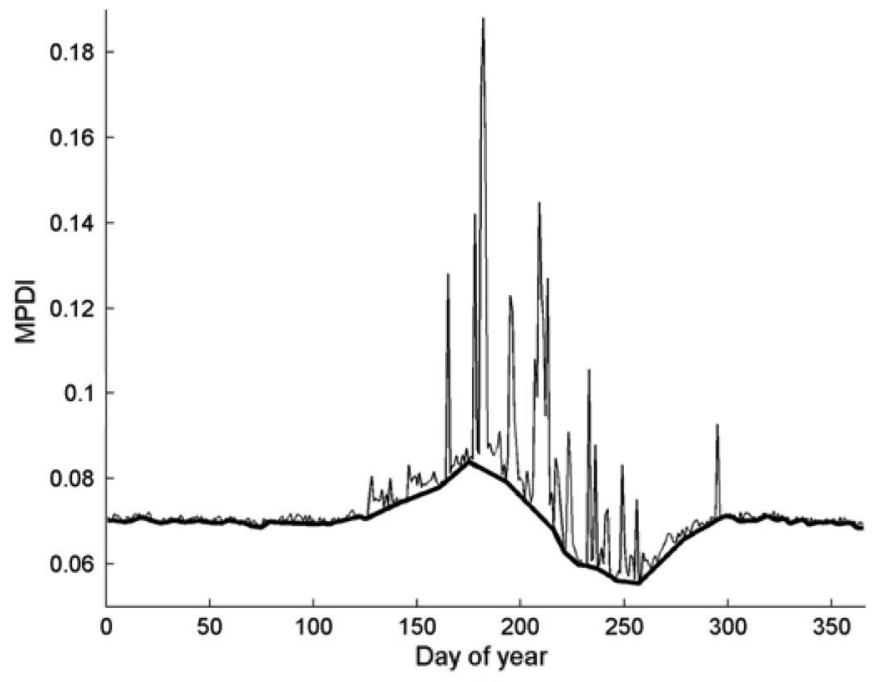

(a)

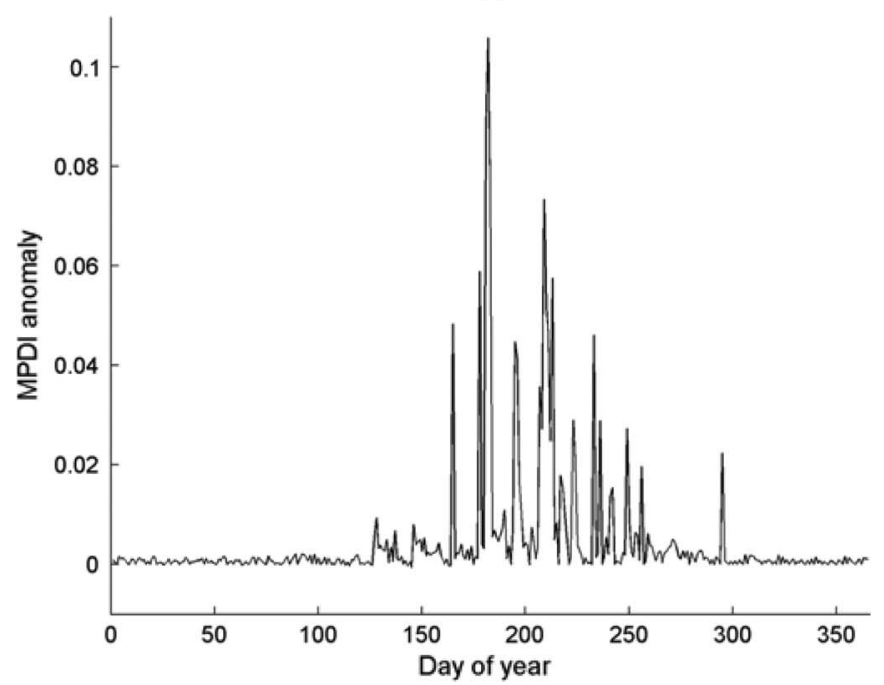

(b)

Fig. 11. Use of AMSR-E polarization difference index (MPDI) to assess the vegetation water content (seasonal trend) and soil moisture (anomaly). (a) MPDI profile (fine line) and seasonal trend (thick line). (b) MPDI anomaly.

following conclusion. Matching between the areas affected by water content and radiometric corrections can be found only in the western part of the mosaic. Here, at higher latitudes (where there is a presence of more open vegetation cover), the radiometric discrepancies between adjacent strips seem to be mostly caused by the effect of vegetation water content [red patterns in Fig. 13(a) and high correction values in Fig. 10], except when this effect is compensated by higher than usual soil moisture [blue patterns in Fig. 13(b)]. At lower latitudes, the radiometric imbalance cannot be explained so far by this type of analysis.

\section{PREliminary Thematic AnAlysis}

Preliminary thematic analysis of the Africa mosaic was conducted with the objective of assessing the potential of the data set for regional scale (e.g., mapping forest resources and forest cover changes) and/or local thematic applications.

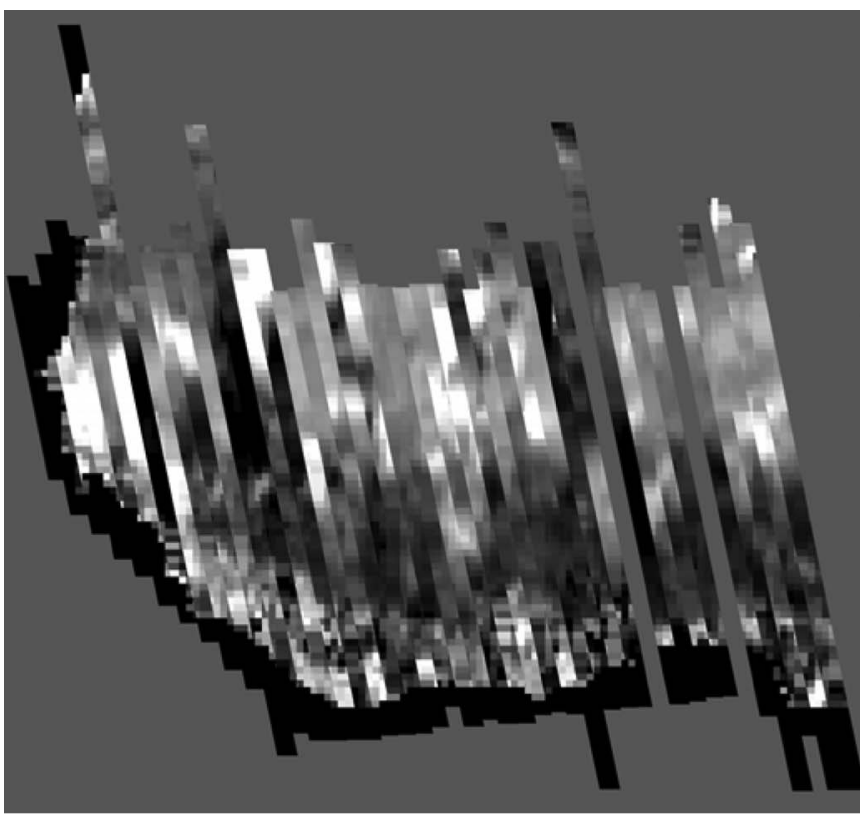

(a)

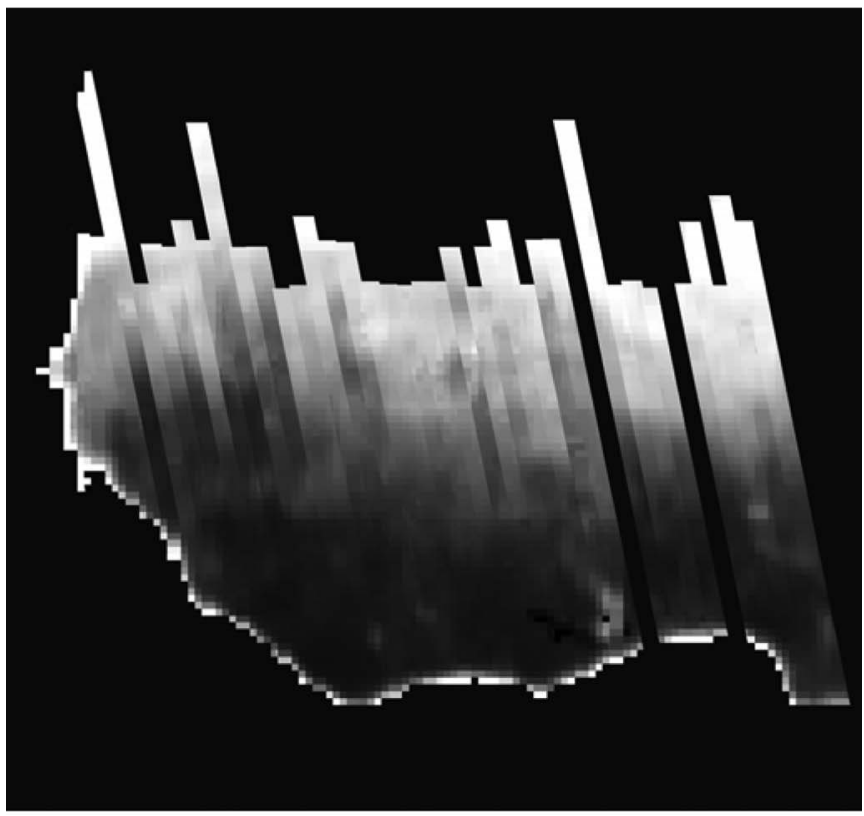

(b)

Fig. 12. Maps of (a) anomaly and (b) seasonal trend derived from AMSR-E data at PALSAR acquisition dates.

The analysis was also undertaken to establish the potential of using the ALOS PALSAR mosaic in combination with optical remote sensing (e.g., MODIS and Landsat TM) for generating a vegetation map of the Africa continent with added-value indicators (e.g., biomass of wooded savannas). In this section, results and observations relating to characterization, mapping, and monitoring of vegetation in the central and western part of the continent are reported. These observations indicate that the Africa mosaic offers a rich source of thematic information, especially for characterizing the humid forest/savanna interface, detecting deforestation and logging patterns, and characterizing dry forest and woodlands at the margin with Saharan Africa. 


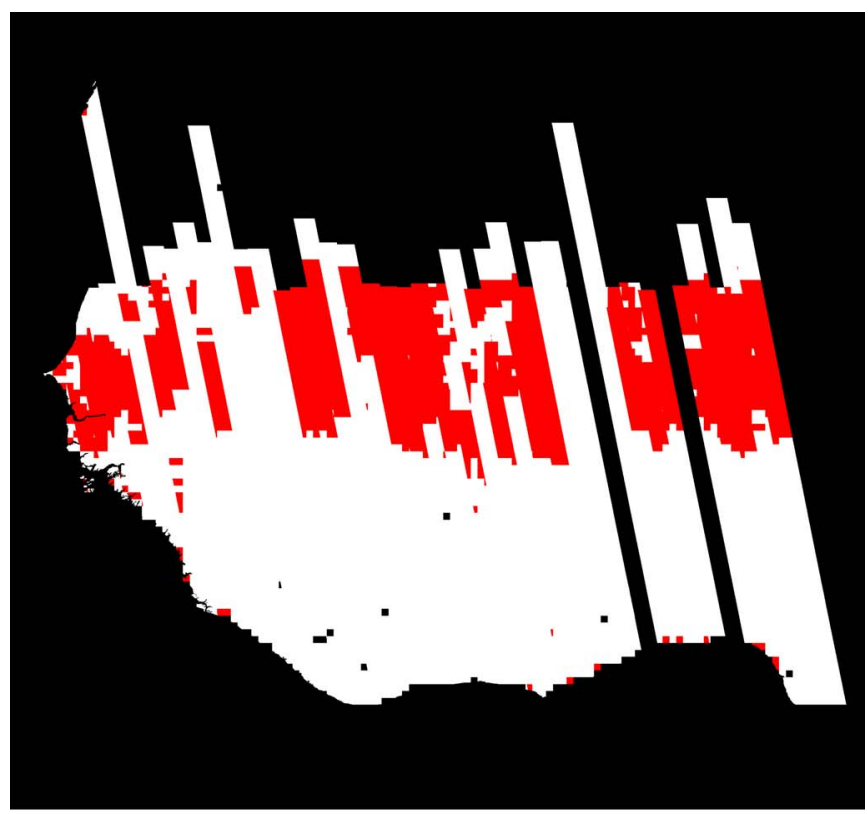

(a)

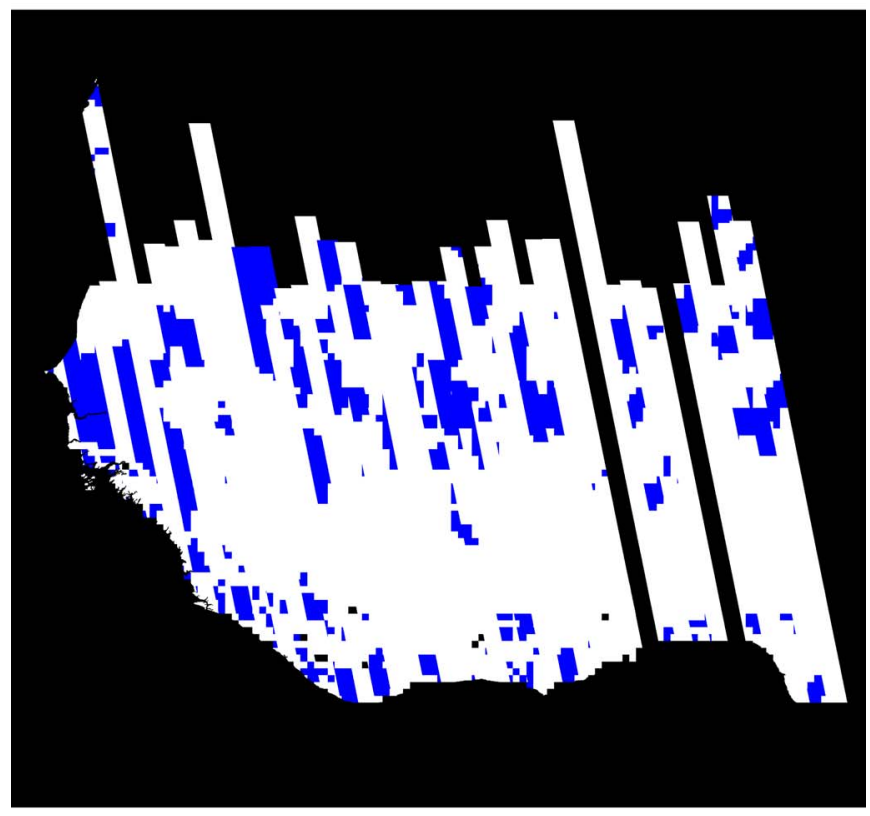

(b)

Fig. 13. Map of regions where vegetation water content is low with respect to the mean annual value [red areas in (a)]. These regions should correspond to strip images featuring a positive correction. Map of regions where soil moisture is high with respect to the annual mean [blue areas in (b)]. These areas should correspond to strip images where a negative correction would be needed.

\section{A. Class Separability and the Role of Polarization Diversity}

A first approximation test was performed to assess the separability of some land-use classes of interest in the feature space of each polarization channel (HH and HV) and of the combination of two polarization channels. This test highlighted the importance of polarization diversity.

A supervised classification of L-band HH and HV polarization data, as well as the HV/HH power ratio, was undertaken based on training areas for the following classes: lowland rain forest, mountain forest, savanna, secondary forest, agriculture,
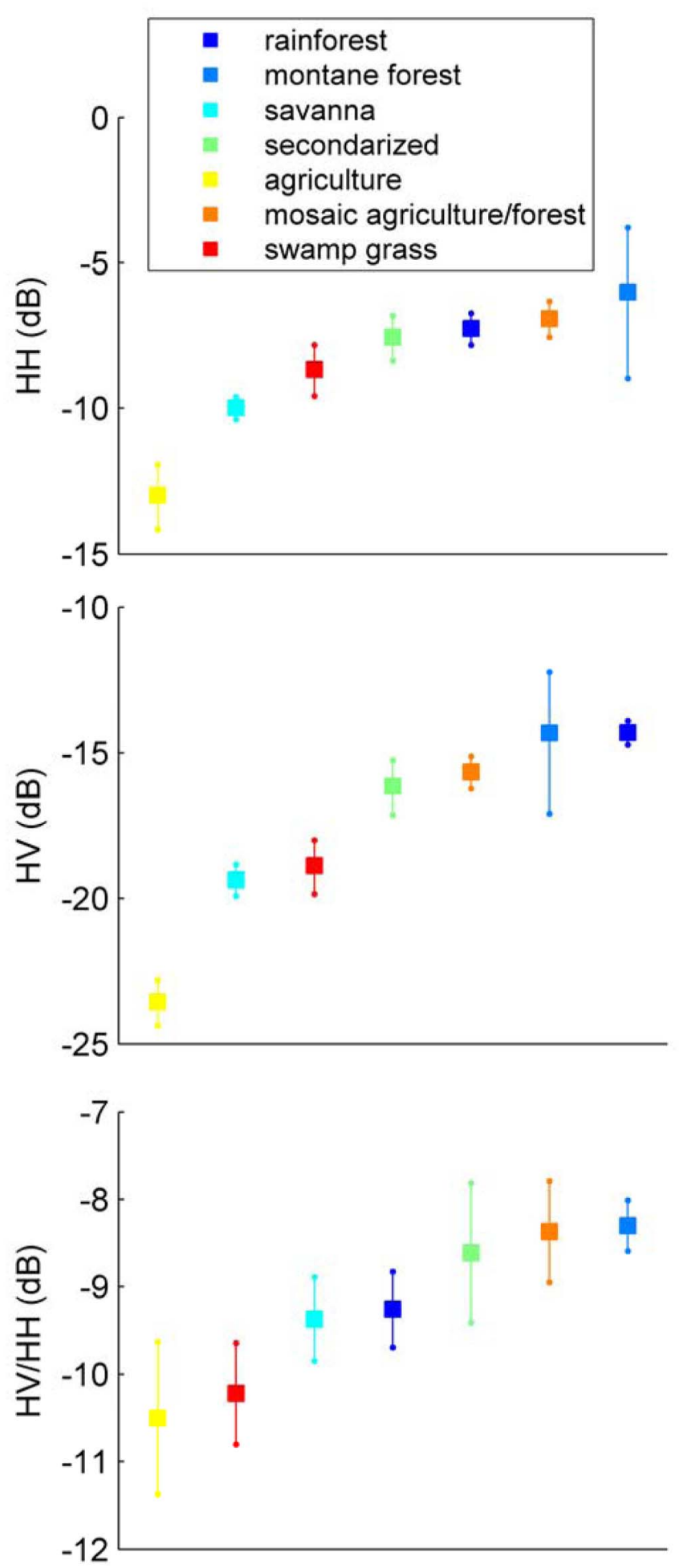

Fig. 14. Estimates of mean backscattering coefficients and standard deviation of the mean for selected classes and for $\mathrm{HH}$ and $\mathrm{HV}$ polarizations and the polarization ratio $\mathrm{HV} / \mathrm{HH}$. These class-separability measures indicate that the polarization ratio performs much better in this context.

and swamp grassland. Secondary forest refers to a mixture of degraded forest and rural complex.

The mean of the backscatter values and the backscatter ratio, together with the standard deviation of the mean, are shown in Fig. 14. Using single polarimetric channels, land 


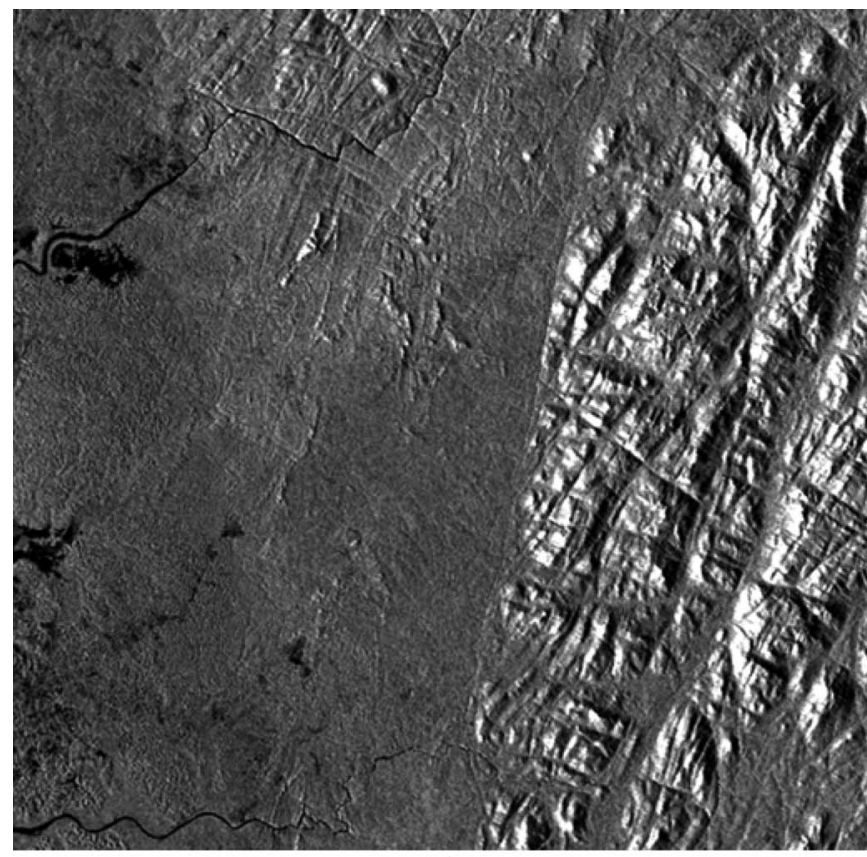

(a)

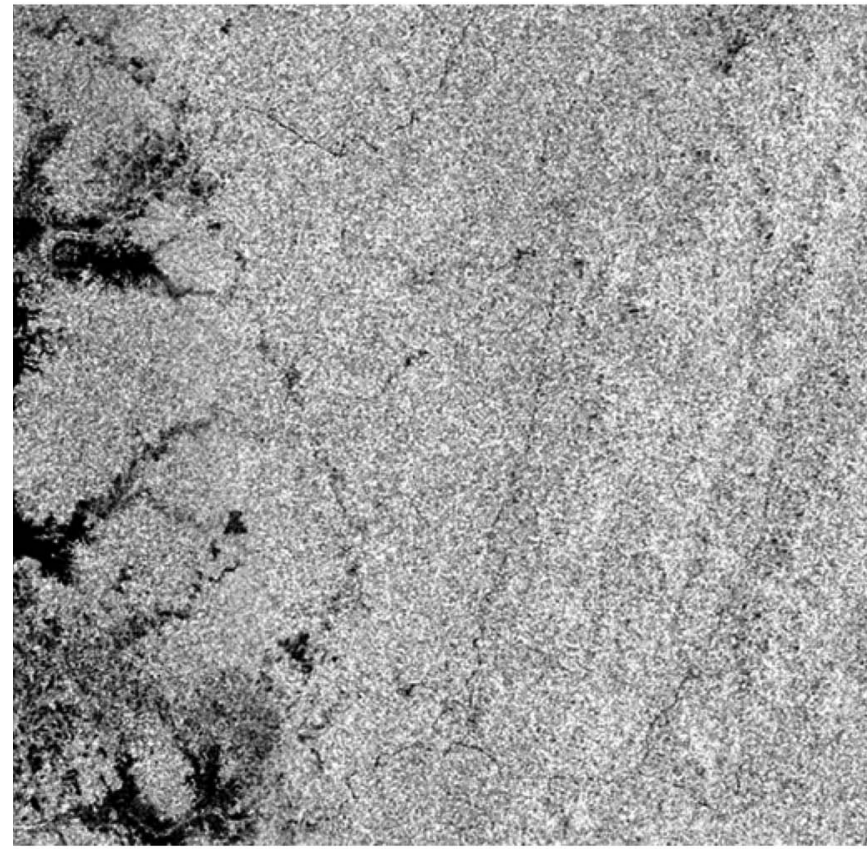

(b)

Fig. 15. Capability of the $\mathrm{HV} / \mathrm{HH}$ polarization ratio in reducing topographic effects.

covers with relatively low backscatter (agriculture, savanna, and swamp grasslands) could be separated from those of higher backscatter (secondary forest, mosaic agriculture/forest, and forest), although, within each group, confusion occurred among all classes at $\mathrm{HH}$ (in line with the analysis reported in [27]), while at $\mathrm{HV}$, the rainforest class was well discriminated.

However, the HV/HH power ratio provided better overall separation, which was attributed partly to reduced dependence on topographic variation. In particular, the ratio decreased the effect of terrain slope as the same effective area is illuminated in both channels and the difference in the radar cross section to local incidence angle between the $\mathrm{HH}$ and $\mathrm{HV}$ channels

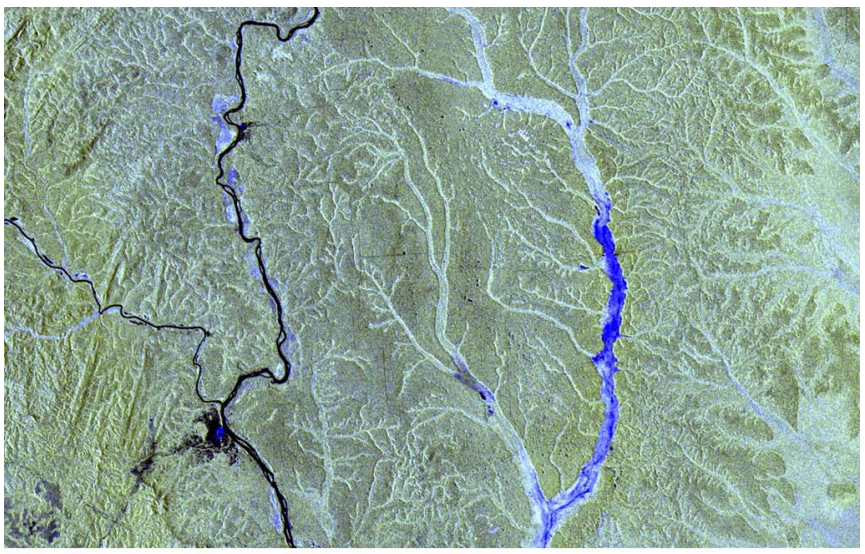

(a)

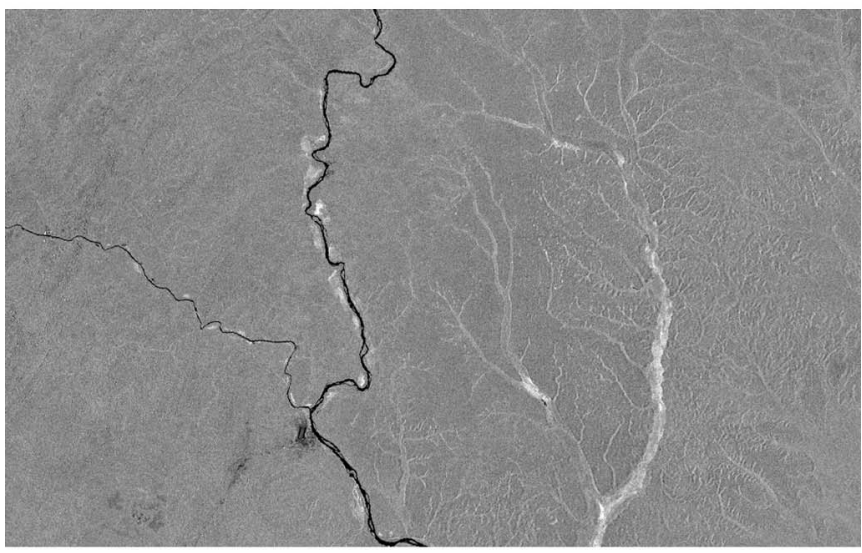

(b)

Fig. 16. (a) PALSAR Africa mosaic's subset of an area near the town of Pokola, Republic of Congo (1.868 N, 16.252 E), acquired in 2007 and (b) corresponding image acquired by JERS-1 in the context of the GRFM project in 1997.

is low. The effectiveness of the $\mathrm{HV} / \mathrm{HH}$ ratio in reducing the topographic effects is shown in Fig. 15. Furthermore, use of the ratio increased vegetation class separability because relative differences in diffuse versus surface scattering were considered.

\section{B. Comparison With the GRFM Africa Data Set}

The availability of the GRFM radar mosaic, derived from JERS-1 acquisitions at HH polarization in 1997 [7], allows ecosystem changes in Central and West Africa over a time span of ten years to be investigated. Automatic change detection between the two data sets will pose some challenges since the two sets were acquired by opposite satellite viewpoints (ascending orbit for PALSAR and descending for JERS-1). However, in flat or gently undulating areas, some comparisons are possible through simple comparison of the imagery, as highlighted in Figs. 16 and 17.

At the northern part of the Republic of Congo, containing the town of Pokola, thin linear features are observed (within the composite of $\mathrm{HH}, \mathrm{HV}$, and $\mathrm{HV} / \mathrm{HH}$ in RGB), with these corresponding to logging roads (Fig. 16). Such features are not detected within the GRFM data sets, which suggests change associated with logging. However, such features may be better 


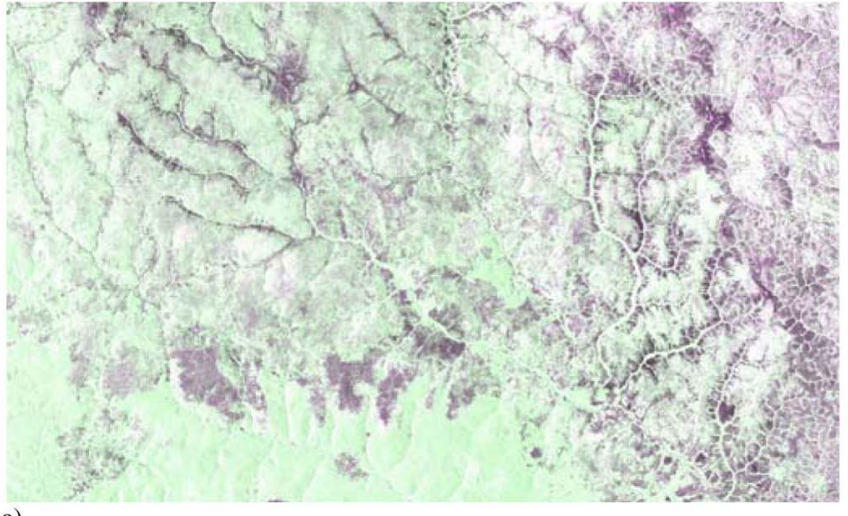

a)

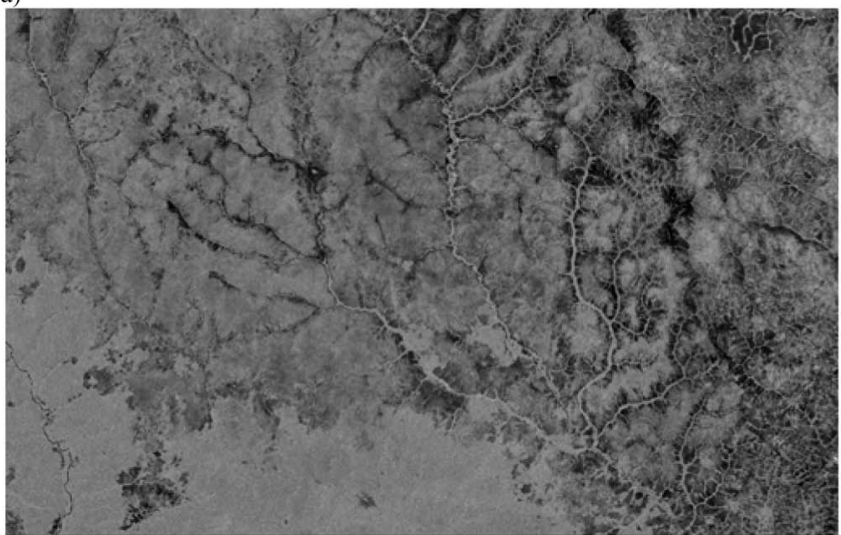

b)

Fig. 17. (a) PALSAR mosaic's subset of an area at the margin between the rain forest and savanna in Central Africa $\left(40^{\circ} 45^{\prime} 36^{\prime \prime} \mathrm{N}, 160^{\circ} 49^{\prime} 37^{\prime \prime} \mathrm{E}\right)$. The corresponding JERS-1 image acquired in 1997 is shown in (b).

detected within the PALSAR because of the better radiometric resolution compared to the JERS-1 SAR.

At the interface between the rainforest and savanna (at $\sim$ latitude $4.4^{\circ} \mathrm{N}$ ), encroachment of the savanna into the rainforest domain is evident, with this attributed to changes in fire and management regimes. However, detection of low biomass vegetation (e.g., savannas) is better using the HV channels, and so, some caution is needed in interpreting these observations.

\section{Differentiation of Vegetation Types}

A preliminary investigation into the ALOS PALSAR mosaics indicates that differentiation of grass and woody savannas and mapping of flooded forests, mangroves, plantations, and secondary forests are achievable. Within the Congo Basin, differences between forests (bright azure), woody (shrub/tree), savannas (orange), and grass savannas (brown) were evident within the ALOS PALSAR data (Fig. 18), with these confirmed through reference to Google Earth optical imagery. ALOS PALSAR observations of swamp forest along the Congo River near Brazzaville (Fig. 19) highlight the enhancement of L-band $\mathrm{HH}$ backscatter from inundated forests. The different shades of orange relate to the state of the surface, with this varying from very wet to flooded. When standing water is present under the canopy, the double-bounce interaction between the surface
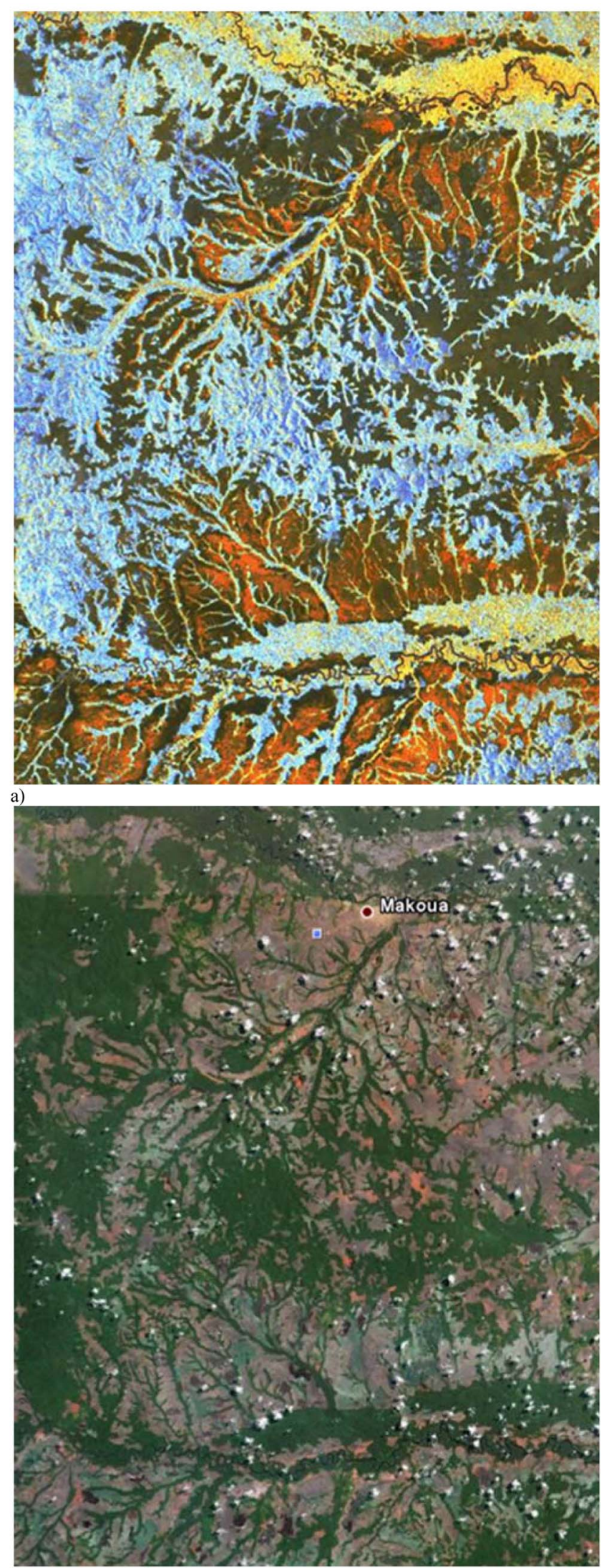

b)

Fig. 18. Mosaic of savanna patches intertwined with the rain forest as portrayed (a) by a PALSAR image (color composite RGBs are $\mathrm{HH}, \mathrm{HV}$, and $\mathrm{HV} / \mathrm{HH}$ ) and (b) by a Google Earth optical image. 

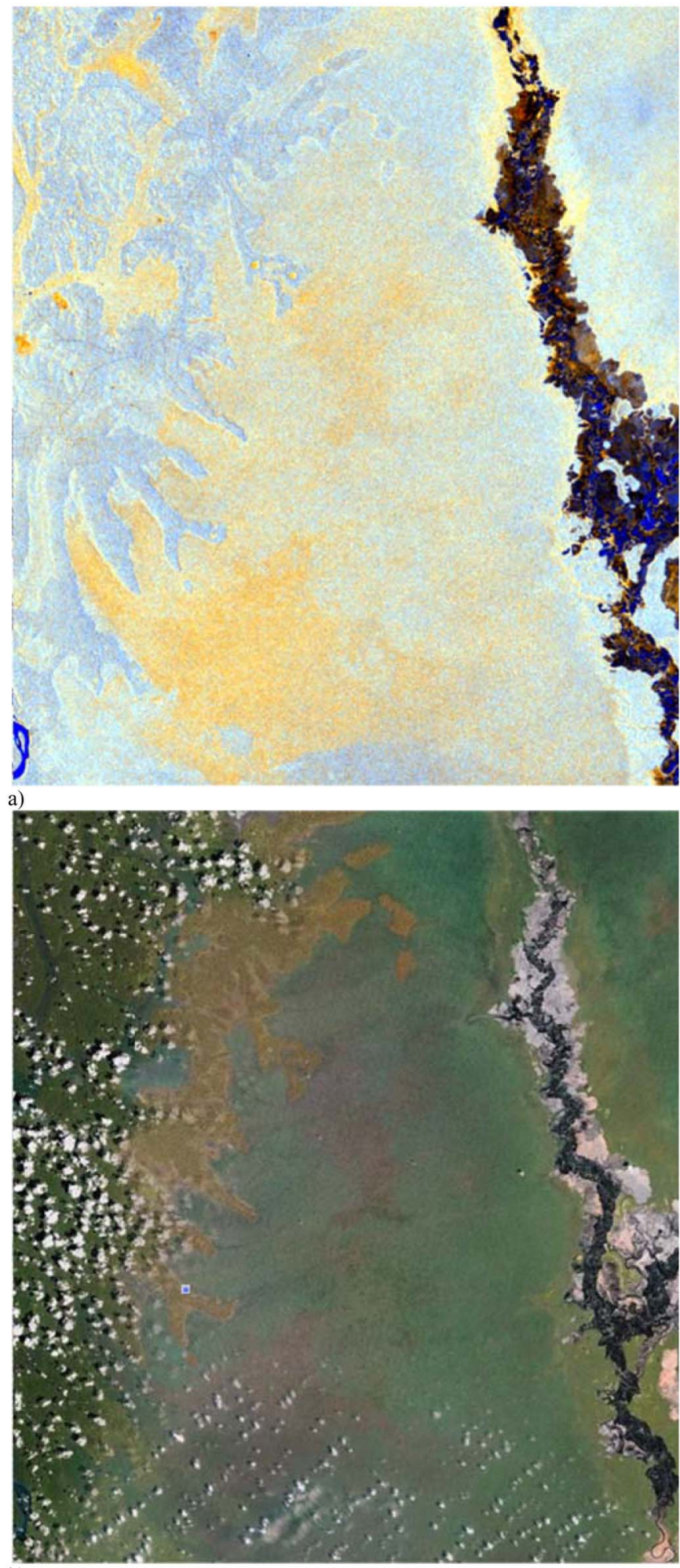

b)

Fig. 19. (a) PALSAR image (color composite RGBs are HH, HV, and $\mathrm{HV} / \mathrm{HH}$ ) of the swamp forest along the Congo river near Brazaville. The different orange shades in the swamp forest at the center of the image indicate the soil state: from very wet to flooded. (b) Optical image from Google Earth is shown for comparison.

and tree trunks increases, leading to greater $\mathrm{HH}$ scattering. By contrast, the HV scattering coefficient, which is associated largely with volume scattering from the canopy, remains similar
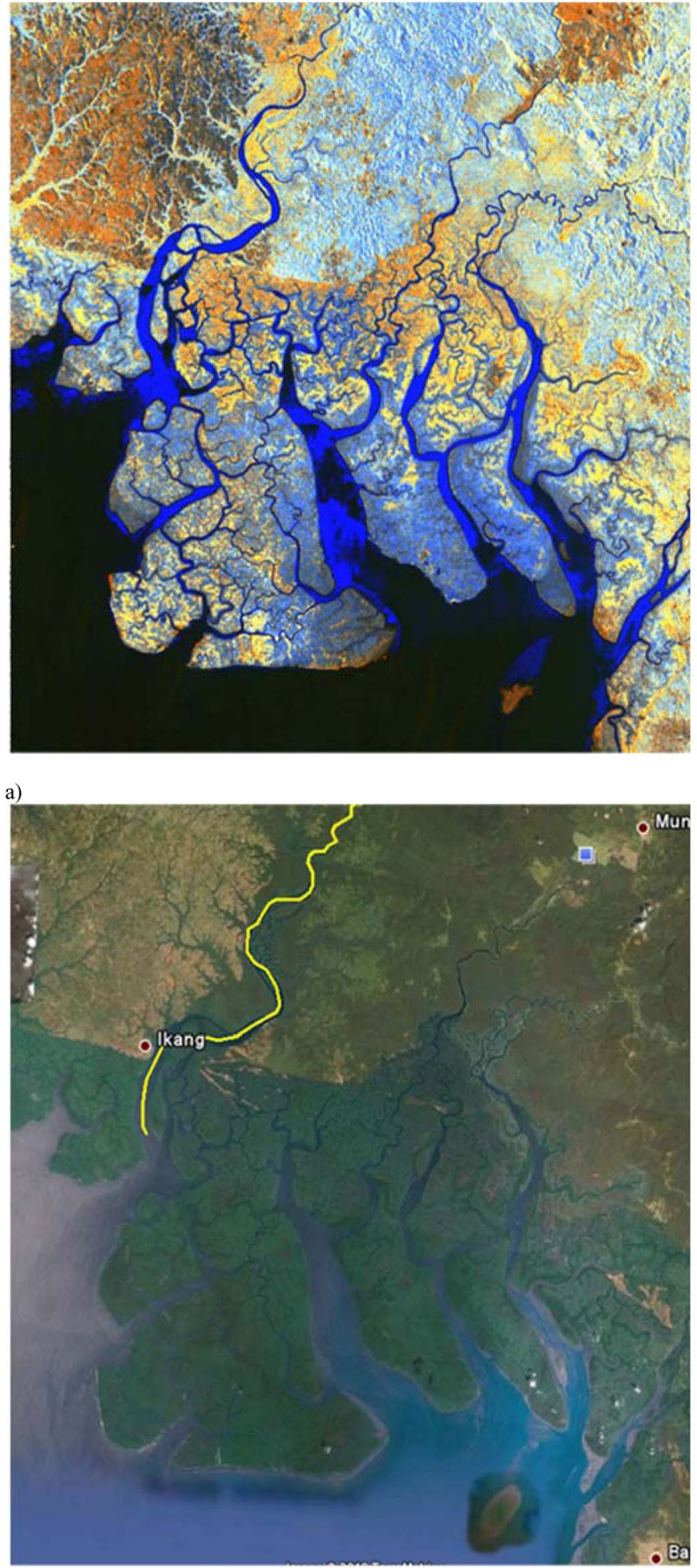

b)

Fig. 20. Coastline with mangrove forests near the Nigeria-Cameroon border as portrayed (a) by a PALSAR image (color composite RGBs are HH, HV, and $\mathrm{HV} / \mathrm{HH}$ ) and (b) by a Landsat image. Radar backscatter distinguishes two types of mangroves (flooded in orange shades and nonflooded in blue shades). Comparison with the Landsat image indicates that this distinction is not possible using optical data.

or can increase only if the crown-stem interaction term is not negligible. Logging roads are also visible within the primary forest (blue) at the left of the image. 


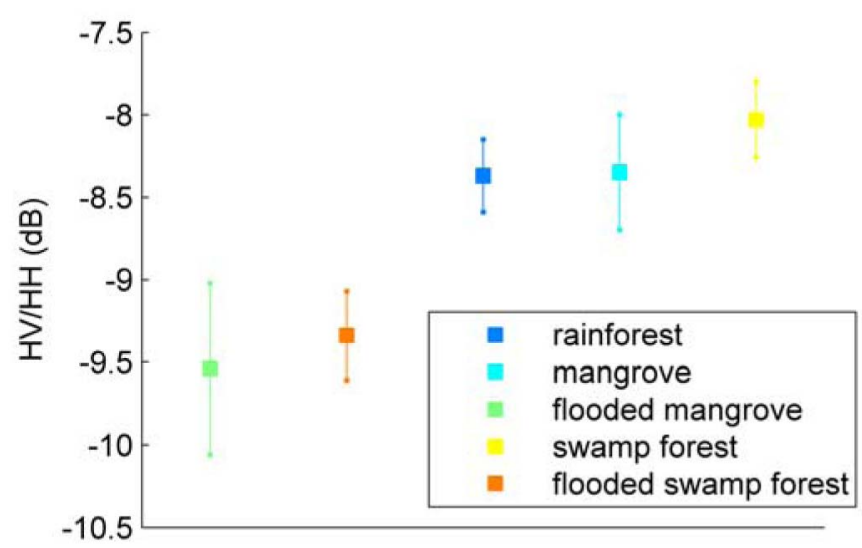

Fig. 21. Analysis of the thematic classes' separability provided by the HV/HH ratio for the data set in Fig. 20. Flooded and nonflooded vegetation classes can be well discriminated using the polarization ratio.

Similarly, mangroves near the border of Nigeria and Cameroon (Fig. 20) are discernible, with variations in backscatter attributed to different structures associated with different species types but also different levels of tidal inundation. Such differences are less evident within the Landsat imagery available through Google Earth. Mangroves can be discriminated from rain and swamp forests by the lower HV backscattering coefficient (about $1.5 \mathrm{~dB}$ lower). Flooded and nonflooded vegetation can be discriminated by using the $\mathrm{HV} / \mathrm{HH}$ ratio, as documented by estimates of the class $\mathrm{HV} / \mathrm{HH}$ mean and variance shown in Fig. 21. The swamp and the rain forest classes cannot be mapped using only one-point statistics (they are not radiometrically pure classes). Two-point statistics (texture) need to be called into play [28].

Plantations are also evident within the PALSAR data, with an example given for an area near Kribi, Cameroon (Fig. 22). The palm oil plantations in this area are evident (bright orange) within the composite of $\mathrm{HH}, \mathrm{HV}$, and $\mathrm{HV} / \mathrm{HH}$ but are not within the corresponding Landsat image. By contrast, plantations of Hevea species are less evident. The combination of ALOS PALSAR and data from optical satellite sensors is therefore advocated for classifying plantation developments. As in other studies [27], differentiation of secondary from primary forest using L-band SAR data is complex and cannot be achieved easily using single-channel data alone. However, the $\mathrm{HV} / \mathrm{HH}$ ratio (Fig. 23) shows differences between the rural complex (with secondary forests) and the surrounding primary forests, as observed within the Google Landsat image (at the right), although delineation is likely to be a significant challenge.

\section{SUMmARY AND CONCLUSION}

Using ALOS PALSAR L-band HH and HV strip data acquired in 2007 and as part of the JAXA K\&C Initiative, a mosaic of the African continent was generated at $100-\mathrm{m}$ spatial resolution. A range of preprocessing routines (radiometric calibration, geocoding, incidence angle, and topographic correction) was implemented to facilitate combining the strip data into the mosaic. However, the backscatter (particularly at $\mathrm{HH}$

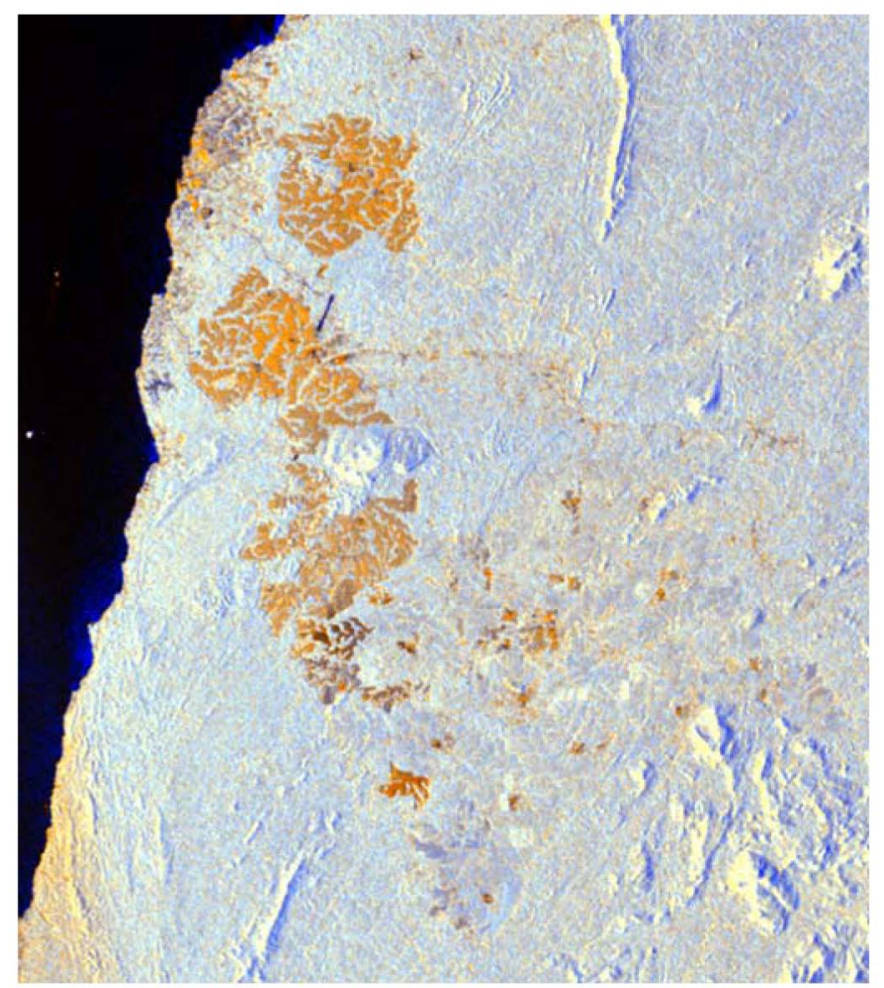

a)

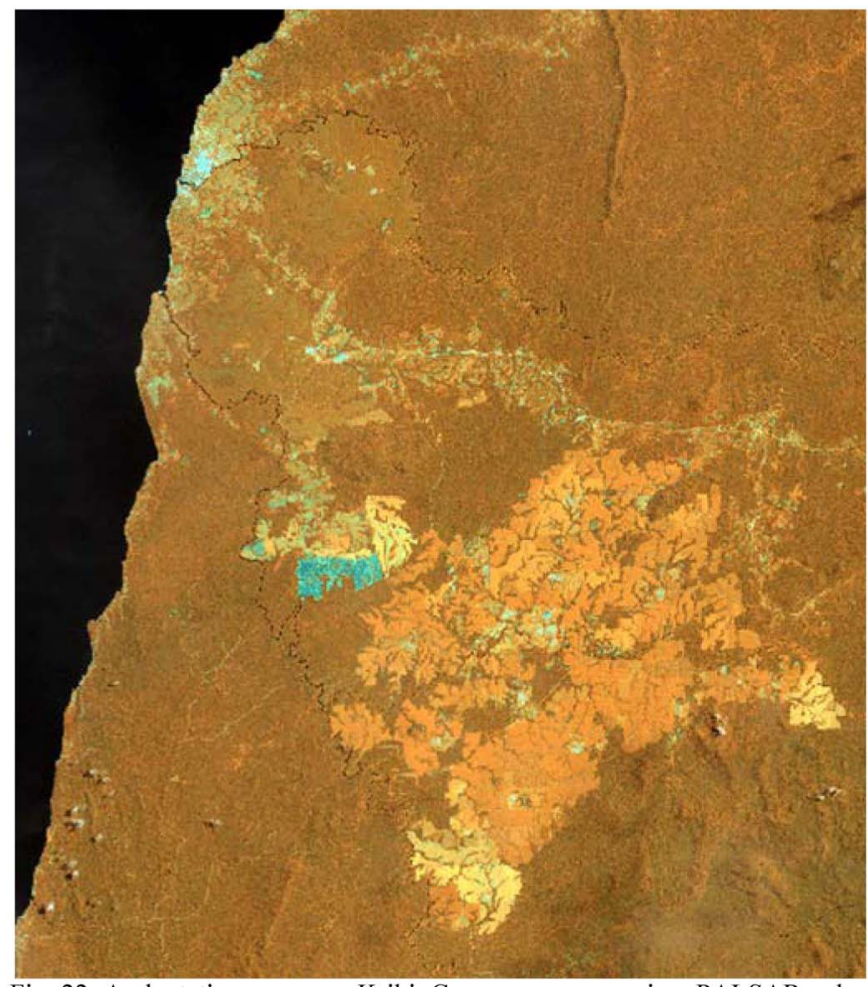

Fig. 22. (a) Plantation area near Kribi, Cameroon, as seen in a PALSAR color composite image. (b) Same area is shown in the Landsat color composite image (band 4-band 5-band 6 in the RGB channels). Bright orange patches represent palm oil plantations in the PALSAR image, but they cannot be detected in the optical image. On the other hand, Hevea plantations appear in the Landsat image (orange patches) but cannot be seen in the PALSAR image.

polarization) was enhanced in some strips, with this attributed to increased vegetation and soil moisture at the time of the ALOS PALSAR data acquisition. 


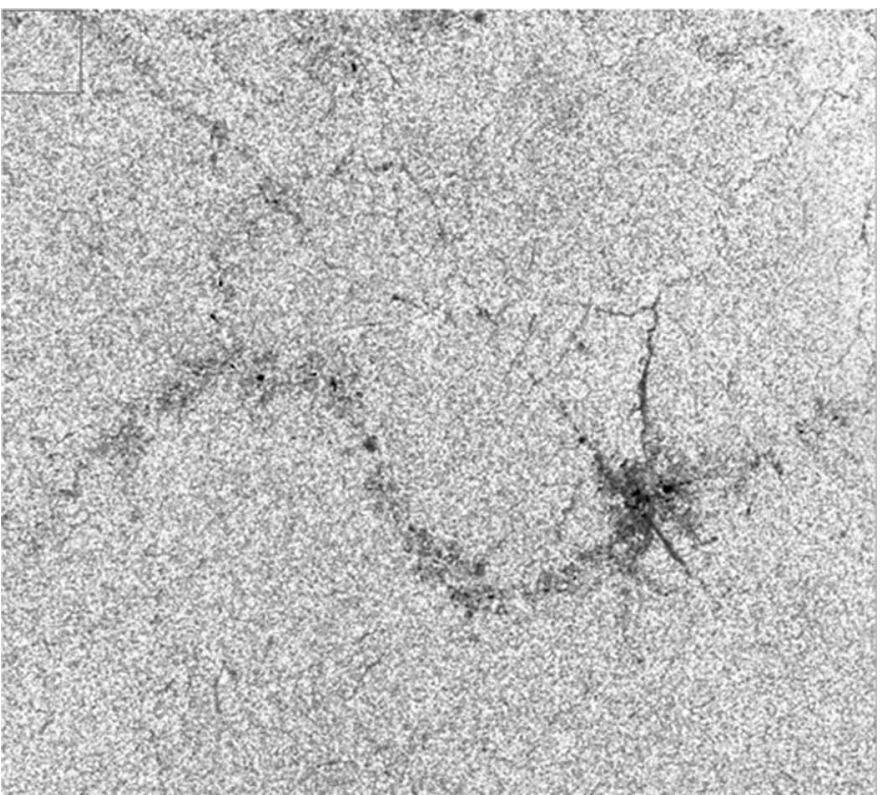

(a)

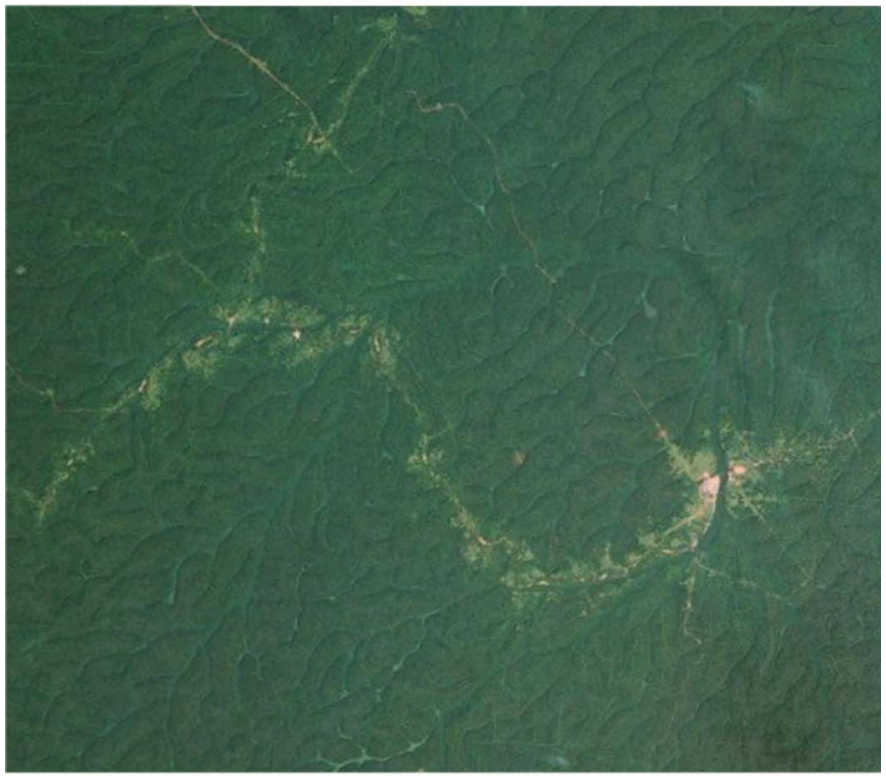

(b)

Fig. 23. Area in South East Cameroon where a secondary forest (a rural complex) emerges from the primary forest as seen (a) from a PALSAR polarization ratio image and (b) from a Landsat image.

A number of potential applications for the mosaic have been highlighted, including mapping of mangroves, plantations, secondary forests, and boundary between savannas and forests. Comparison with the JERS-1 SAR mosaics suggests significant potential for detecting changes in vegetation cover associated with deforestation and encroachment.

\section{ACKNOWLEDGMENT}

The authors would like to thank JAXA for providing PALSAR imagery through the ALOS K\&C Initiative and the anonymous reviewers for their contribution toward improving this paper.

\section{REFERENCES}

[1] A. Rosenqvist, R. M. Lucas, B. Chapman, J. Lowry, L. Hess, and P. Paillou, "The ALOS Kyoto \& Carbon Initiative, Science Plan v.3.1," JAXA Earth Obs. Res. Center, Tsukuba, Japan, 2008.

[2] A. Rosenqvist, M. Shimada, and A. K. Milne, "The ALOS Kyoto \& Carbon Initiative," in Proc. IGARSS, 2007, pp. 3614-3617.

[3] A. Rosenqvist, M. Shimada, N. Ito, and M. Watanabe, "ALOS PALSAR: A pathfinder mission for global-scale monitoring of the environment," IEEE Trans. Geosci. Remote Sens., vol. 45, pt. 1, no. 11, pp. 3307-3316, Nov. 2007.

[4] M. Shimada, O. Isoguchi, and A. Rosenqvist, "PALSAR calval and generation of the continent scale mosaic products for Kyoto and Carbon projects," in Proc. IEEE IGARSS, 2008, vol. 1, pp. I-17-I-20.

[5] W. T. K. Johnson, "Magellan imaging radar mission to Venus," Proc. IEEE, vol. 79, no. 6, pp. 777-790, Jun. 1991.

[6] G. F. De Grandi, J. P. Malingreau, and M. Leysen, "The ERS-1 Central Africa mosaic: A new perspective in radar remote sensing for the global monitoring of vegetation," IEEE Trans. Geosci. Remote Sens., vol. 37, no. 3, pp. 1730-1746, May 1999.

[7] G. F. De Grandi, P. Mayaux, Y. Rauste, A. Rosenqvist, M. Simard, and S. Saatchi, "The Global Rain Forest Mapping Project JERS-1 radar mosaic of tropical Africa: Development and product characterization aspects," IEEE Trans. Geosci. Remote Sens., vol. 38, no. 5, pp. 2218-2233, Sep. 2000.

[8] A. Rosenqvist, M. Shimada, B. Chapman, K. McDonald, G. De Grandi, H. Jonsson, C. Williams, Y. Rauste, M. Nilsson, D. Sango, and M. Matsumoto, "An overview of the JERS-1 SAR Global Boreal Forest Mapping (GBFM) project," in Proc. IEEE IGARSS, 2004, vol. 2, pp. 1033-1036.

[9] P. Siqueira, S. Hensley, S. Shaffer, L. Hess, G. McGarragh, B. Chapman, and A. Freeman, "A continental-scale mosaic of the Amazon Basin using JERS-1 SAR," IEEE Trans. Geosci. Remote Sens., vol. 38, no. 6, pp. 2638-2644, Nov. 2000.

[10] L. Pierce and O. Barros, "A dual-frequency SAR mosaic of the Amazon," in Proc. IEEE IGARSS, 2010, pp. 4671-4674.

[11] A. L. Mitchell, A. Milne, I. Tapley, K. Lowell, P. Caccetta, E. Lehmann, and Z.-S. Zhou, "Wall-to-wall mapping of forest extent and change in Tasmania using ALOS PALSAR data," in Proc. IEEE IGARSS, 2010, pp. 1230-1233.

[12] M. Shimada and T. Ohtaki, "Generating large-scale high-quality SAR mosaic data sets: Application to PALSAR data for global monitoring," IEEE J. Sel. Topics Appl. Earth Obs. Remote Sens., vol. 3, pt. 2, no. 4, pp. 637-656, Dec. 2010.

[13] A. Jarvis, H. I. Reuter, A. Nelson, and E. Guevara, Hole-Filled SRTM for the Globe Version 4, available from the CGIAR-CSI SRTM $90 \mathrm{~m}$ Database, 2008. [Online]. Available: http://srtm.csi.cgiar.org

[14] K. J. Bhang, F. W. Schwartz, and A. Braun, "Verification of the vertical error in C-band SRTM DEM using ICESat and Landsat-7, Otter Tail County, MN," IEEE Trans. Geosci. Remote Sens., vol. 45, no. 1, pp. 3644, Jan. 2007.

[15] SARscape Short Technical Description, sarmap SA. [Online]. Available: http://www.sarmap.ch/pdf/SARscapeTechnical.pdf

[16] W. Albright and J. Nicoll, "Empirical determination of thermal noise levels in synthetic aperture radar," in Proc. IEEE IGARSS, 2002, vol. 5, pp. 2729-2731.

[17] G. Schreier, J. Raggam, and D. Strobl, "Parameters for geometric fidelity of geocoded SAR products," in Proc. IEEE IGARSS, 1990, pp. 305-308.

[18] J. J. Van Zyl, "The effect of topography on radar scattering from vegetated areas," IEEE Trans. Geosci. Remote Sens., vol. 31, no. 1, pp. 153-160, Jan. 1993.

[19] F. Holecz, U. Wegmüller, E. Rignot, and Y. Wang, "Observed radar backscatter from forested areas with terrain variations," in Proc. IEEE Int. Geosci. Remote Sens. Symp., Firenze, Italy, 1995, vol. 1, pp. 613-615.

[20] T. Castel, A. Beaudoin, N. Stach, N. Stussi, T. Le Toan, and P. Durand, "Sensitivity of space-borne SAR data to forest parameters over sloping terrain. Theory and experiment," Int. J. Remote Sens., vol. 22, no. 12, pp. 2351-2376, 2001.

[21] J. Kropáček, G. De Grandi, and Y. Rauste, "Georeferencing of continental scale JERS-1 SAR mosaics based on matching homologous features with a digital elevation model: Theory and practice," Int. J. Remote Sens., to be published.

[22] R. M. Lucas, J. A. Armston, R. Fairfax, R. Fensham, A. Accad, J. Carreiras, J. Kelly, P. Bunting, C. Clewley, S. Bray, D. Medcalfe, M. Dwyer, M. Bowen, T. Eyre, M. Laidlaw, and M. Shimada, "An evaluation of the ALOS PALSAR L-band backscatter-Above ground biomass relationship Queensland, Australia: Impacts of surface moisture condition 
and vegetation structure," IEEE J. Sel. Topics Appl. Earth Obs. Remote Sens., vol. 3, no. 4, pp. 576-593, Dec. 2010.

[23] E. Bartholomé and A. Belward, "GLC2000: A new approach to global land cover mapping from Earth observation data," Int. J. Remote Sens., vol. 26, no. 9, pp. 1959-1977, 2005.

[24] E. G. Njoku, T. J. Jackson, V. Lakshmi, T. K. Chan, and S. V. Nghiem, "Soil moisture retrieval from AMSR-E," IEEE Trans. Geosci. Remote Sens., vol. 41, no. 2, pp. 215-229, Feb. 2003.

[25] M. Owe, R. de Jeu, and J. Walker, "A methodology for surface soil moisture and vegetation optical depth retrieval using the microwave polarization difference index," IEEE Trans. Geosci. Remote Sens., vol. 39, no. 8, pp. 1643-1654, Aug. 2001.

[26] C. Gruhier, P. de Rosnay, Y. Kerr, E. Mougin, E. Ceschia, J.-C. Calvet, and P. Richaume, "Evaluation of AMSR-E soil moisture product based on ground measurements over temperate and semi-arid regions," Geophys. Res. Lett., vol. 35, p. L10 405, 2008.

[27] P. Mayaux, G. De Grandi, and J. P. Malingreau, "Central Africa forest cover revisited: A multi-satellite analysis," Remote Sens. Environ., vol. 71, no. 2, pp. 183-196, Feb. 2000

[28] G. D. De Grandi, R. M. Lucas, and J. Kropacek, "Analysis by wavelet frames of spatial statistics in SAR data for characterizing structural properties of forests," IEEE Trans. Geosci. Remote Sens., vol. 47, no. 2, pp. 494-507, Feb. 2009.

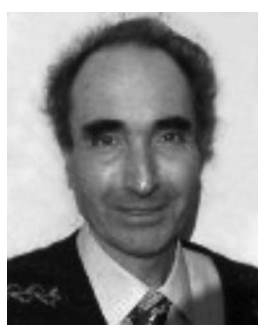

Gianfranco D. De Grandi (M'90-SM'96-F'02) received the Doctorate degree in physics engineering (with honors) from the Politecnico Milano, Milano, Italy, in 1973.

Since 1977, he has been with the Directorate General Joint Research Center, European Commission, Ispra, Italy, where he has performed research in signal processing for application areas such as gamma ray spectroscopy, data communications, and radar remote sensing. In 1985, he was a Visiting Scientist at Bell Communications Research, Morristown, NJ, where he participated in the design of METROCORE, which is one of the first research projects for gigabit-rate metropolitan area networks. From 1997 to 2001, he served as an Assistant Professor with the Faculte' de Feresterie et Geomatique, Universite' Laval, Quebec, PQ, Canada. His current research interest includes global-scale forest mapping using high-resolution spaceborne synthetic aperture radar (SAR), wavelet multiresolution techniques for the approximation and analysis of SAR imagery, topography sensing using polarimetric SAR data, and statistics of polarimetric synthesized SAR images. He was a Principal Investigator of the Japan Aerospace Exploration Agency (JAXA) Global Boreal Forest Mapping project, the JAXA ALOS research program, and the JAXA Kyoto and Carbon $(\mathrm{K} \& \mathrm{C})$ project, and he is a Principal Investigator of the German Aerospace Center (DLR) Tandem-X mission.

Dr. De Grandi was elected as an IEEE Fellow in 2002, with the following citation: For contributions to continental-scale vegetation mapping using highresolution SAR mosaics, and in the area of information extraction from SAR data. He is a member of the IEEE Geoscience and Remote Sensing Society, the IEEE Signal Processing Society, and the Planetary Society, Pasadena, CA.

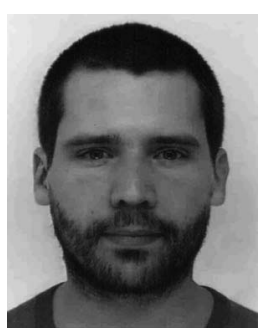

Alexandre Bouvet received the Engineering degree from the Ecole Nationale Supérieure d'Aéronautique et de l'Espace, Toulouse, France, in 2004 and the $\mathrm{Ph}$.D. degree from the Centre d'Etudes Spatiales de la Biosphère, Université Paul Sabatier-Toulouse III, Toulouse, in 2009.

Since 2010, he has been a Postdoctoral Fellow with the Joint Research Center, European Commission, Ispra, Italy, where he is working on the use of synthetic aperture radar (SAR) data for the analysis of tropical forest cover dynamics. His interests include SAR image processing and the use of remote sensing data to monitor vegetated areas for environmental applications.

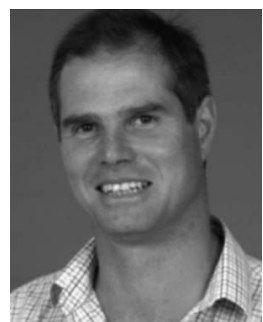

Richard M. Lucas received the B.Sc. degree in biology and geography (first class) and the Ph.D. degree in remote sensing of snow and vegetation using NOAA AVHRR and Landsat sensor data from the University of Bristol, Bristol, U.K., in 1986 and 1989, respectively.

$\mathrm{He}$ is currently a Professor with the Institute of Geography and Earth Sciences, Aberystwyth University, Aberystwyth, U.K., where he is involved primarily in the integration of single-date and time-series synthetic aperture radar, optical (hyperspectral), and LiDAR data for retrieving the biomass, structure, and species/community composition of ecosystems ranging from subtropical woodlands to tropical forests and mangroves. He is also a Principal Investigator and a science team member within the Japan Space Exploration Agency Kyoto and Carbon Initiative. His research focuses on carbon dynamics and biodiversity of these systems and their response to natural and human-induced change. He has authored or coauthored over 100 journal articles, book chapters, and conference papers.

Masanobu Shimada (M'97-SM'04-F'11) received the B.S. and M.S. degrees in aeronautical engineering from Kyoto University, Kyoto, Japan, in 1977 and 1979, respectively, and the Ph.D. degree in electrical engineering from the University of Tokyo, Tokyo, Japan, in 1999.

Since 1979, he has been with the National Space Development Agency of Japan (NASDA), Tokyo, which is currently the Japan Aerospace Exploration Agency (JAXA). He has been assigned duties at the Earth Observation Research Center, where he serves as the ALOS Science Manager, is responsible for ALOS CAL/VAL, global forest mapping projects, and synthetic aperture radar (SAR) interferometry projects since 1995, and is currently a Principal Researcher. With JAXA, he designed a NASDA scatterometer. From 1985 to 1995, he developed data processing subsystems for optical and SAR data (i.e., MOS-1, SPOT, and JERS-1) at the Earth Observation Center. He was a Visiting Scientist at the Jet Propulsion Laboratory in 1990.

Stefano Monaco received the M.S. degree in information science from the Universita' degli Studi, Milan, Italy, in 1992.

From 1992 to 1999, he was with ETNOTEAM s.p.a., Milan, where he was involved in the design, coding, and testing of software for GSM mobile systems. In 1999, he joined sarmap SA, Purasca, Switzerland, where he is a Principal Engineer in charge of designing, coding, and testing software modules for synthetic aperture radar image processing.

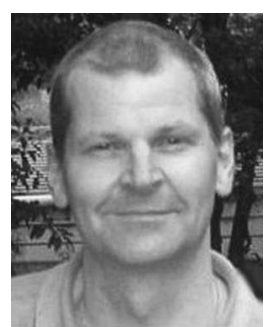

Ake Rosenqvist received the M.S. degree in surveying from the Royal Institute of Technology, Stockholm, Sweden, in 1988 and the Dr. Eng. degree in microwave remote sensing from the University of Tokyo, Tokyo, Japan, in 1997.

He joined the Swedish Space Corporation in 1990 where he was engaged in the French/Swedish SPOT programme. As first foreign national, he was invited to the National Space Development Agency of Japan, Tokyo, in 1993, where he became involved in the development of the JERS-1 application program and the establishment of the JERS-1 SAR Global Forest Mapping project. He spent six years at the European Commission Joint Research Centre, Ispra, Italy, and another five years as Senior Scientist at the Japan Aerospace Exploration Agency (JAXA), where he developed the concept of systematic data observations, which was adopted by JAXA and implemented for the ALOS mission. $\mathrm{He}$ founded solo Earth Observation (soloEO), Tokyo, in 2009 and is currently involved in the GEO Forest Carbon Tracking Task, coordination of the K\&C Initiative, and supporting the development of systematic acquisition strategies for the ALOS-2 and Argentinean SAOCOM-1 missions.

Dr. Rosenqvist was awarded the ISPRS President's Honorary Citation in 2000 